\title{
Review \\ Sirtuins as Important Factors in Pathological States and the Role of Their Molecular Activity Modulators
}

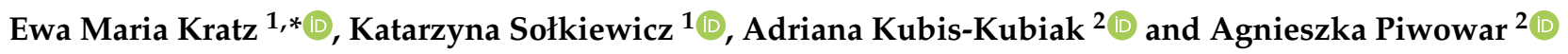 \\ 1 Department of Laboratory Diagnostics, Division of Laboratory Diagnostics, Faculty of Pharmacy, \\ Wroclaw Medical University, 50-556 Wroclaw, Poland; katarzyna.solkiewicz@umed.wroc.pl \\ 2 Department of Toxicology, Faculty of Pharmacy, Wroclaw Medical University, 50-556 Wroclaw, Poland; \\ adriana.kubis-kubiak@umed.wroc.pl (A.K.-K.); agnieszka.piwowar@umed.wroc.pl (A.P.) \\ * Correspondence: ewa.kratz@umed.wroc.pl; Tel.: +48-(71)-784-01-52
}

Citation: Kratz, E.M.; Sołkiewicz, K.;

Kubis-Kubiak, A.; Piwowar, A

Sirtuins as Important Factors in Pathological States and the Role of Their Molecular Activity Modulators. Int. J. Mol. Sci. 2021, 22, 630. https:// doi.org/10.3390/ijms22020630

Received: 13 December 2020 Accepted: 7 January 2021

Published: 10 January 2021

Publisher's Note: MDPI stays neutral with regard to jurisdictional clai$\mathrm{ms}$ in published maps and institutional affiliations.

Copyright: (C) 2021 by the authors. Licensee MDPI, Basel, Switzerland. This article is an open access article distributed under the terms and conditions of the Creative Commons Attribution (CC BY) license (https:// creativecommons.org/licenses/by/ $4.0 /)$

\begin{abstract}
Sirtuins (SIRTs), enzymes from the family of $\mathrm{NAD}^{+}$-dependent histone deacetylases, play an important role in the functioning of the body at the cellular level and participate in many biochemical processes. The multi-directionality of SIRTs encourages scientists to undertake research aimed at understanding the mechanisms of their action and the influence that SIRTs have on the organism. At the same time, new substances are constantly being sought that can modulate the action of SIRTs. Extensive research on the expression of SIRTs in various pathological conditions suggests that regulation of their activity may have positive results in supporting the treatment of certain metabolic, neurodegenerative or cancer diseases or this connected with oxidative stress. Due to such a wide spectrum of activity, SIRTs may also be a prognostic markers of selected pathological conditions and prove helpful in assessing their progression, especially by modulating their activity. The article presents and discusses the activating or inhibiting impact of individual SIRTs modulators. The review also gathered selected currently available information on the expression of SIRTs in individual disease cases as well as the biological role that SIRTs play in the human organism, also in connection with oxidative stress condition, taking into account the progress of knowledge about SIRTs over the years, with particular reference to the latest research results.
\end{abstract}

Keywords: sirtuins expression; sirtuin activators; sirtuin inhibitors; sirtuins in pathological conditions; oxidative stress

\section{Introduction}

The change in gene expression accompanying gene inheritance does not have to be related to the direct modification of the genetic code, but may also take place through an extra-genomic mechanism, which is related to the ability to modify the histone proteins included in the chromatin, strongly bound to the DNA helix. The most important mechanisms of these changes are the processes of acetylation and deacetylation of lysine, an abundant component of histones. Post-translational modifications of histone proteins may also occur as a result of their methylation, phosphorylation or ubiquitination, but the acetylation/deacetylation mechanism is the most common [1]. The two main families of enzymes involved in the processes of histone acetylation and deacetylation (histone acetyltransferases, HATs and histone deacetylases, HDACs, which include sirtuins, SIRTs) [2,3], also play an important role in the process of post-translational modifications [3]. The main biochemical processes that take place in the human body with the participation of SIRTs are shown in Figure 1. 


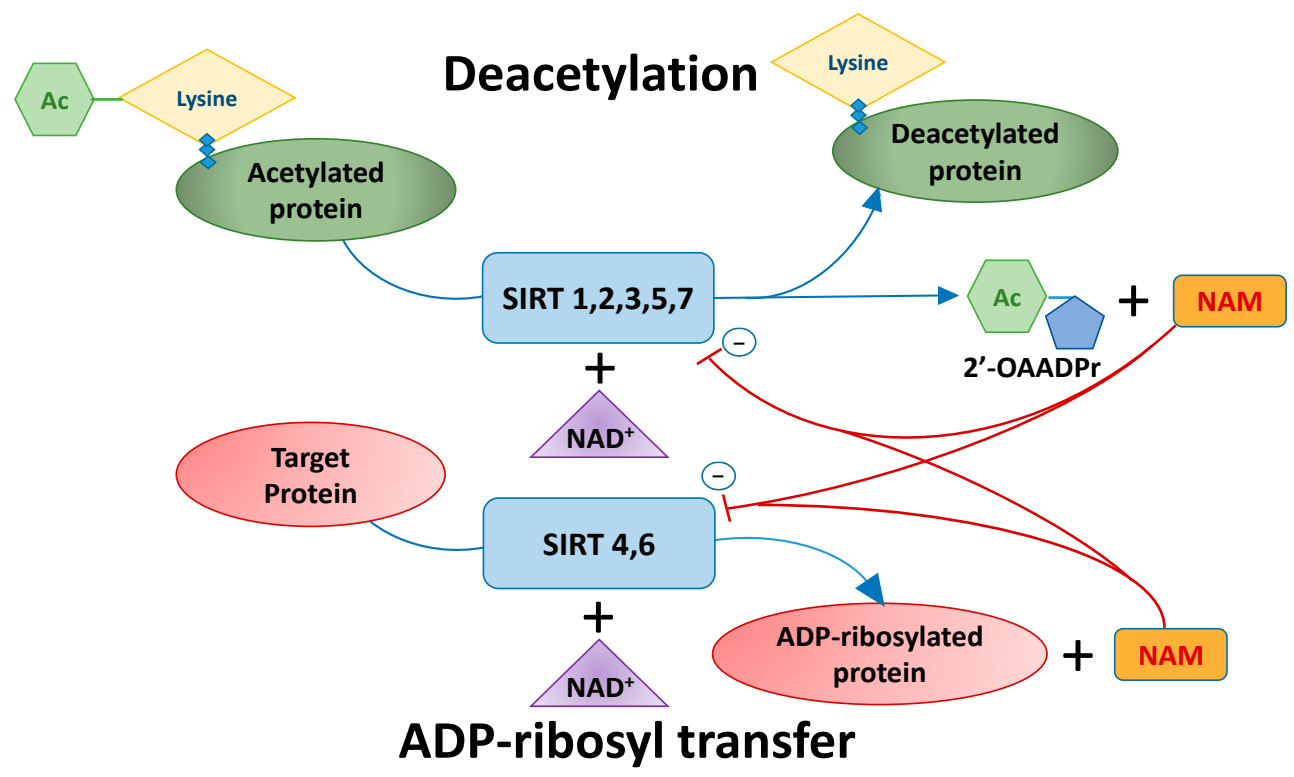

Demalonylation and desuccinylation

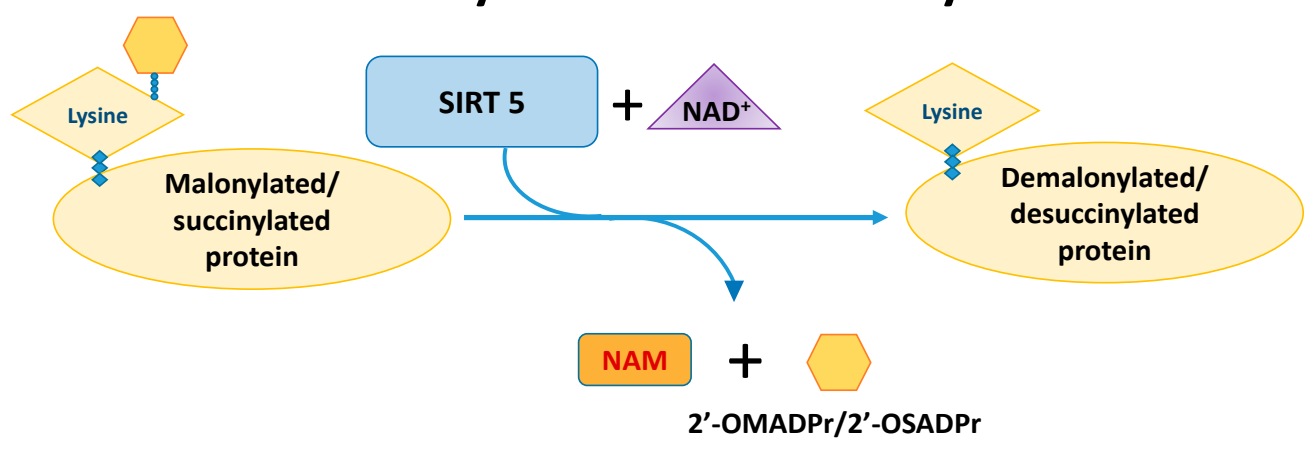

Figure 1. Enzymatic activity of the SIRTs. NAD ${ }^{+}$is a substrate for all SIRTs in reaction of nicotinamide (NAM) production. In the deacylation reaction, $\mathrm{NAD}^{+}$receives the acetyl (Ac) group from the protein. The adenine dinucleotide moiety from $\mathrm{NAD}^{+}$is linked to various residues on the target protein in ADP-ribosyl transfer. SIRT1, 2, 3, 5 and 7 show the lysine deacetylation activity of target proteins in which the $\mathrm{NAD}^{+}$coenzyme is used to produce NAM and $2^{\prime}$-O-acetyl-ADP-ribose (2'-OAADPr). SIRT4 exhibits only ADP-ribosyl transferase activity, and NAD ${ }^{+}$is used as a donor of the ADP-ribose group for target proteins. ADP-ribosyl transferase activity shares with SIRT6. SIRT5 uses NAD ${ }^{+}$as a cofactor in the demalonylation and desuccinylation of target proteins, generating NAM and 2'-O-malonyl-ADP-ribose (2'-OMADPr) and 2'-O-succinyl-ADP-ribose (2'-OSADPr), respectively. Modification based on Morigi et al. [4,5].

SIRTs are enzyme proteins that belong to the nicotinamide adenine dinucleotide $\left(\mathrm{NAD}^{+}\right)$family of histone deacetylases. The structure, biological functions, target location, and the main substrates of catalytic activity have been discussed in detail in numerous reviews [6-9]. Table 1 shows the structure of the SIRTs and their target location. 
Table 1. Human SIRTs—structure and target location.

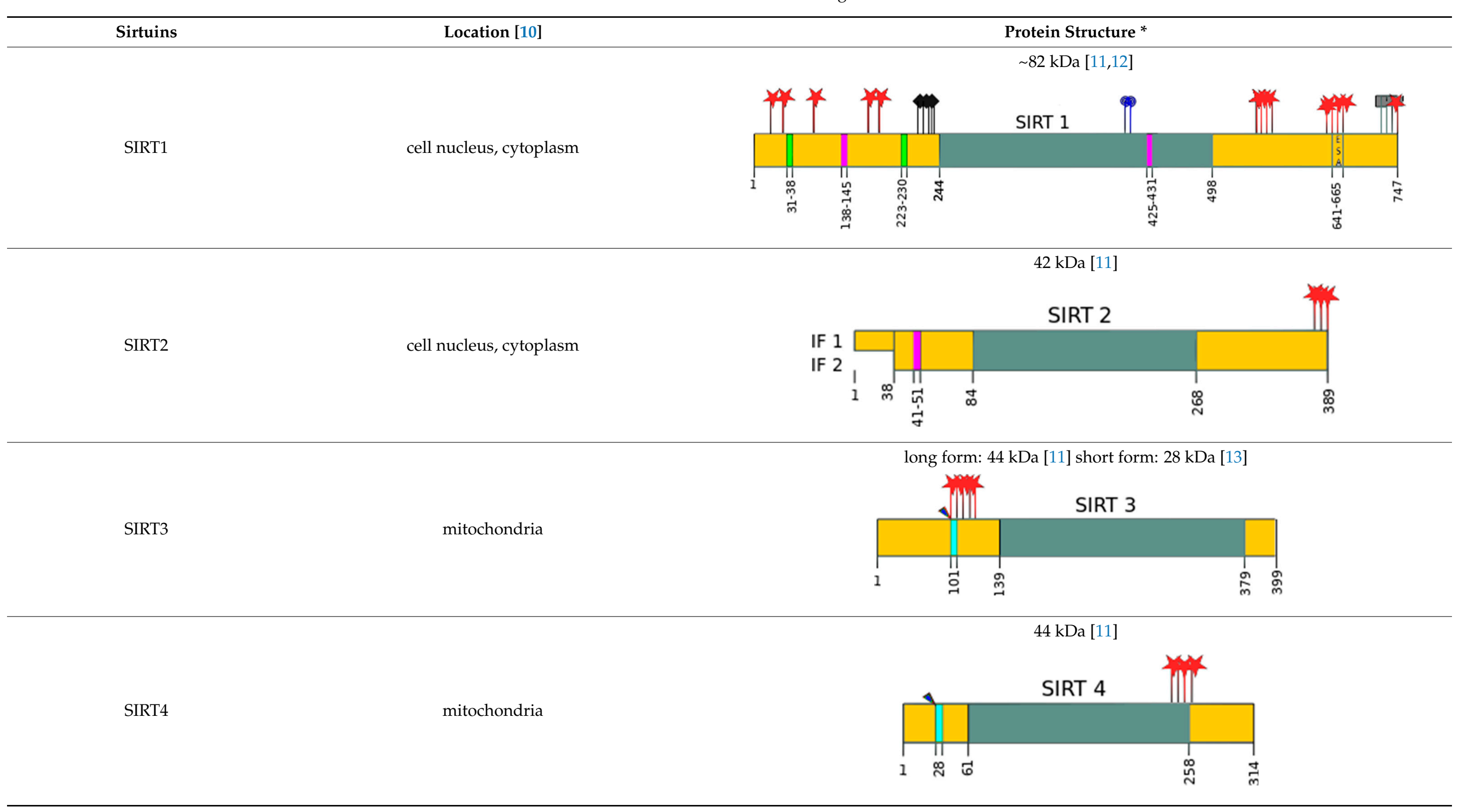


Table 1. Cont.

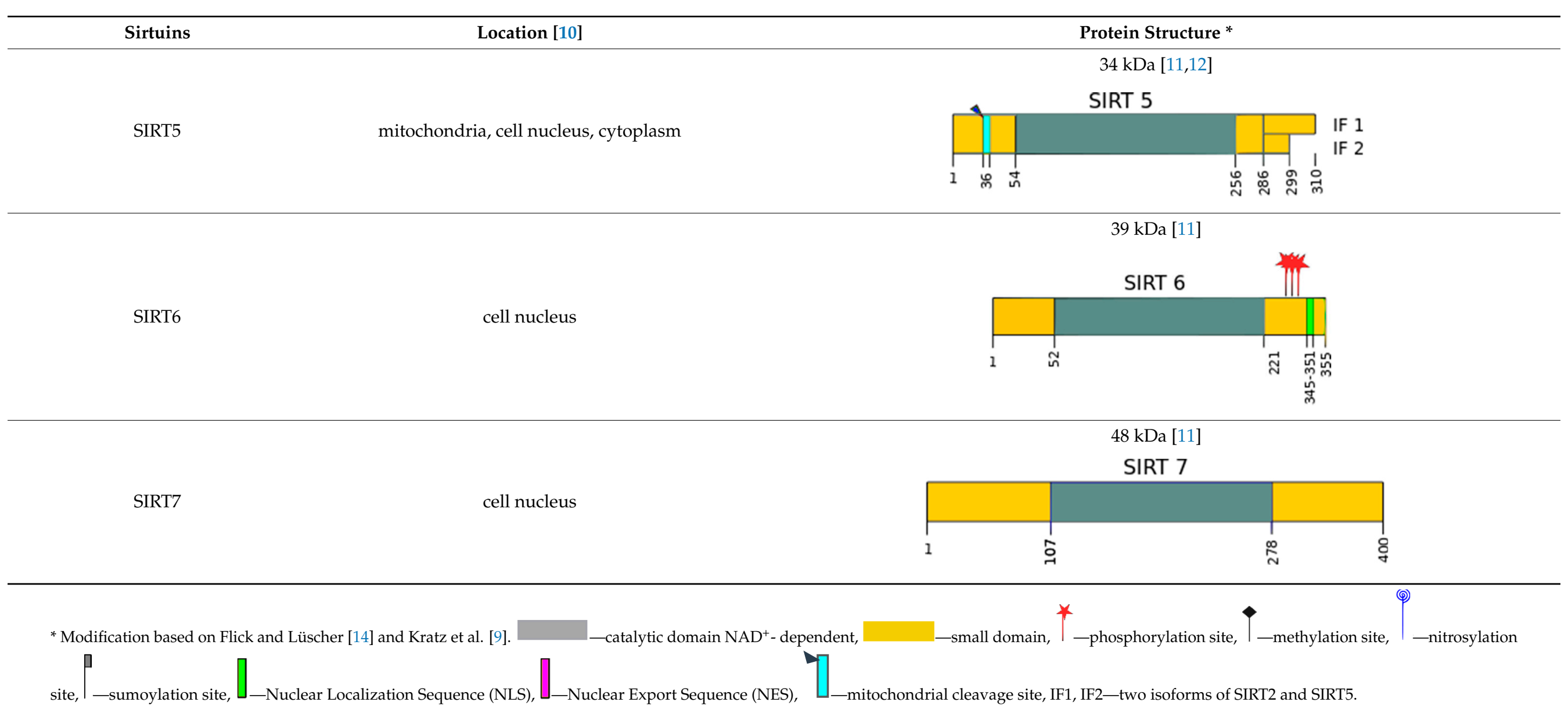


SIRTs are present in all living organisms, and in addition to regulating the degree of histone acetylation, they are also involved in many other processes that take place within the cell, including involvement in the regulation of the cell cycle and energy metabolism, as well as in the process of cell differentiation, growth and apoptosis. The role of SIRTs has also been proven in the response of cells to different types of stress, e.g., oxidative, energetic or induced by ultraviolet radiation or through action on various target substrates $[3,15]$. Many scientific studies focus on the analysis of the activity changes of SIRTs in pathological conditions, ranging from neurodegenerative diseases, through liver ailments, digestive system maladies, infertility and insulin resistance, to neoplastic states and oxidative stress conditions [16-19]. Due to such a wide range of activities, SIRTs have aroused particular interest among researchers in recent years. Latest observations give high hopes for the use of these proteins for diagnostic purposes as markers of disease progression, but also for therapeutic purposes based on their activation or inhibition, in order to increase the effectiveness of patients' treatment.

This study collects information from latest reports while also taking into account the advancement of knowledge about SIRTs over the years. It characterizes the most important currently recognized SIRTs modulators that may have an activating or inhibitory impact. The participation of SIRTs and the degree of their expression in selected disease entities is also presented and discussed in the context of their main roles in the organism.

\subsection{Sirtuins and Oxidative Stress}

Growing evidence provides information that supports the substantial role of SIRTs family in the regulation of cellular homeostasis, in particular metabolism and oxidative stress [20,21]. An environment of oxidative stress is said to be a consequence as well as a reason for conditions such as metabolic syndrome or obesity. It seems that, as SIRTs controls metabolic responses, it can also have an impact on the general disruption of redox cellular homeostasis [22-24]. The fact that SIRTs deacetylase activity is dependent on $\mathrm{NAD}^{+}$, a key redox signaling molecule, may support the idea that sirtuins may be important players in regulating cellular antioxidant and redox signaling (ARS) pathways. The coenzyme $\mathrm{NAD}^{+}$ mediates redox reactions by carrying electrons from one reaction to another, being an oxidizing agent, which accepts an electron, as well as may converts into its reduced form, $\mathrm{NADH}$, and vice versa [25]. The overwhelmed generation of ROS can also affect SIRTs' activity at genetic, posttranslational modification, and protein-protein interaction levels. For example, oxidative stress increases expression and, as a consequence, the activity of SIRT 1, leading to higher levels of their deacetylated substrates such as transcription factor p53, forkhead box proteins $\mathrm{O}$ or peroxisome proliferator-activated receptor gamma coactivator 1 alpha (PGC1 $\alpha)$. As a result of the aforementioned alterations, stronger antioxidative response is detected via SOD2, glutathione peroxidase or catalase expression [26-30]. On the other hand, some in vitro data shows that exposition to high doses of $\mathrm{H}_{2} \mathrm{O}_{2}(100 \mu \mathrm{M}$ or $250 \mu \mathrm{M}$ ) significantly decreased SIRT1 protein activity and gene expression [31-33]. Posttranslational modifications triggered by oxidative stress, such as phosphorylation of SIRT at different C-terminal residues or sumoylation, has been shown to upregulate its enzymatic activity [34]. Kinases such as Cdc2 or Casein Kinase II, regulated by oxidative stress, are known to phosphorylate SIRT on the C-terminus domain [35,36]. 5'AMP-activated protein kinase-a crucial regulator of the redox state of the cell, the biological activity of which is regulated by oxidative stress - can also phosphorylate SIRT, mainly by affecting binding to its protein inhibitor [37,38]. Mutations of different sites on SIRT1 affect cell cycle progression, trigger a conformational change reflected in enzymatic activity alterations, or lead to yet unexamined functional consequences [39-41]. Oxidative modifications of SIRTs are less well studied. Yang et al. [42] have shown that SIRT1 undergoes covalent oxidative modification by cigarette smoke-derived oxidants and aldehydes, leading to its inactivation and degradation. There is also a study that reports treatment of HEK293 cells with nitrosoglutathione resulting in nitrosylation of nuclear SIRT1 and inhibited deacetylation of PGC1 $\alpha$, a known regulator of the expression of mitochondrial antioxidants such as 
SOD2 [43]. Treatment of recombinant SIRT6 with the peroxynitrite donor SIN-1 revealed nitration of the enzyme and diminished activity [44]. Another mechanism by which oxidative stress regulates the activity of different SIRTs is by altering their binding to regulatory proteins. In the case of SIRT1, it promotes the phosphorylation of protein (DBC1) deleted in breast cancer 1, which increases its affinity for SIRT1, leading to SIRT inhibition [45]. It is still unknown whether the active regulator of SIRT1—another regulatory protein — plays an active role in the mediation of response to oxidative stress in cells [46,47]. As NAD ${ }^{+}$ availability is key in the regulation of all SIRTs, the inhibition of major $\mathrm{NAD}^{+}$-consuming enzymes such as poly(ADP-ribose) polymerase 1 (PARP-1), or the genetic deletion or pharmacological inhibition of the protein CD38 (the main NAD glycohydrolase), activates SIRT1 and protects against metabolic and age-related diseases [48-51]. However, SIRT1 is the most well-studied member of the mammalian sirtuin family, also in context of its connection with oxidative stress, it is known that all of the mammalian sirtuins may be associated with oxidative stress signaling and antioxidant defense in the cell [24,25], with particular emphasis on sirtuins located in mitochondria which are involved in maintaining redox homeostasis in the cell. One of them is SIRT3 which full-length form resides in the nucleus but trans-locates to the mitochondria in response to stress, e.g., DNA damage [52]. SIRT3 is known to mediate the flow of mitochondrial oxidative pathways and therefore regulate the production of ROS [53], and can affect cellular health directly by influencing the production of ROS through modulation of enzymes involved in the mitochondrial oxidative phosphorylation (OXPHOS) pathway [54]. Human mitochondrial DNA (mtDNA) encodes for 13 proteins, which are known to play a role in regulating respiration and OXPHOS in the mitochondria, and is significantly more susceptible to oxidative damage than nuclear DNA [55]. In the cell, ROS generated by OXPHOS, ionizing radiation, or chemicals are responsible for DNA damage, including changing purine and pyrimidine bases to 8-oxo-7,8-dihydroguanine (8-oxoG). Importantly, SIRT3 has been shown to target the enzyme that repairs this DNA damage, human 8-oxoguanine-DNA glycosylase 1 (OGG1). SIRT3 has been shown to promote OGG1 by binding to it to prevent degradation and control its activation when DNA glycosylase becomes active. Moreover, SIRT3 has been found to be crucial in the repair of mtDNA, protecting the integrity of mitochondria, and protecting the cell from apoptosis under conditions of oxidative stress by mediating the activity and replenishment of OGG1 [56]. Thus, SIRT3 has an important role in protecting the cell against genotoxic stress and oxidative damage, underlining its importance in ARS. SIRT4 is also a mitochondrial sirtuin which the main function is ribosylation of adenosine diphosphate (ADP) [57,58]. Unlike other sirtuins, SIRT4 was initially thought to not have $\mathrm{NAD}^{+}$-dependent deacetylase activity. Recently, however, SIRT4 was found to have the ability to deacetylate lysine, allowing it to control leucine metabolism and insulin secretion [57]. Furthermore, some authors suggest that all the sirtuins, except SIRT4, play a key role in the reduction of mitochondrial oxidative stress throughout the caloric restriction process $[59,60]$. This, however, does not minimize the role played by SIRT 4 in oxidative stress regulation in the cell. SIRT4 has been shown to be involved in the regulation of ROS production in mitochondria, although it is unclear if it affects the activation of antioxidant enzymes localized to the mitochondrial matrix [59,60]. Mitochondrial SIRT5 functions is deacetylation, demalonylation, and desuccinylation multiple proteins [58,61]. SIRT5 play a role in cellular metabolism, detoxification, regulation of oxidative stress, energy production, and mediation of the apoptosis pathway [62]. However, there is no definitive on the roles of SIRT5 in these processes, and many conflicting views seem to exist in this regard, it appears that its association with ROS and oxidative stress signaling is strong. SIRT5 is popularly known for the regulation of mitochondrial fatty acid oxidation, the urea cycle, and cellular respiration $[63,64]$. SIRT5 deacetylates and activates carbamoyl phosphate synthetase (CPS1), which catalyzes the first step of the urea cycle for the detoxification of ammonia [63] which is known to induce ROS production and decrease antioxidant GSH content [65], suggesting the indirect involvement of SIRT5 in managing oxidative stress. SIRT5 has also been shown to deacetylate cytochrome $C$, which is an essential component 
of the electron transport chain [66]. In a Liang et al. study [67], cells that were transfected with SIRT5 were found to have decreased levels of ROS, suggesting that SIRT5 suppresses the progression of oxidative stress conditions in the cell. Overall, it appears that SIRT5 play an important role in a response of cells to oxidative stress. However, this area of research still needs further efforts aimed at elucidating the exact mechanism of SIRT5 functions [24]. Delicate modifications to the expression and activity of SIRTs are crucial to maintain cellular homeostasis. Although it's clear that SIRTs are modulated by oxidative stress, the molecular mechanisms that underlay this relation are not well understood. Active SIRTs can defend cells from ROS-induced destruction via their product, O-acetyl-ADP-ribose, which hinders mitochondrial ROS assembly and raises NADPH levels from the pentose phosphate pathway $[24,68]$.

\subsection{The Sirtuin-Nrf2 Interaction}

Nuclear factor E2-related factor 2 (Nrf2) is generally recognized as a transcription factor activated by oxidative stress that induces the production of antioxidant proteins and supports the regulation of redox homeostasis. Nrf2, which is naturally bound to Kelch-like ECH-associated protein 1 in the cytoplasm, where it undergoes proteolytic degradation and rapid turnover, is then phosphorylated, and translocated to the nucleus. It binds to the antioxidant response element target genes and increases the transcription of a variety of anti-oxidative and multiple cytoprotective enzymes, including NADPH-quinone oxidoreductase 1, glutathione S-transferases, and heme oxygenase-1 [69,70]. The function of the Nrf2-antioxidant pathway is controlled by multiple factors, including the acetylationdeacetylation of Nrf2. While SIRT1 and NRF2 are typically believed to function via separate pathways, recent evidence suggests SIRT1 involvement in regulating the expression and activation of Nrf2 [24]. Kawai et al. [71] demonstrated that SIRT1-mediated deacetylation of the Nrf2 protein terminated the transcription of antioxidant genes in vitro. However, other studies have demonstrated that SIRT1 overexpression significantly promoted the nuclear accumulation, DNA binding and transcriptional activity of Nrf2 and Nrf2-mediated gene expression [72,73]. Some studies have shown that the transcriptional activity of Nrf2 can be regulated by SIRTs, which upregulate Nrf2 downstream gene expression of genes encoding superoxide dismutase and glutation [72,74]. Conversely, downregulation of SIRT1 expression significantly reduced Nrf2 protein expression. Others found that overexpression can deacetylate Nrf2 and surge the stability as well as stimulate the transport of Nrf2 to the nucleus. Moreover, it promotes the transcriptional activity of Nrf2 and improves the resistance of cells to oxidative damage. In mouse type II alveolar epithelial cells exposed to paraquat (herbicide strongly toxic to humans), the SIRT1/Nrf2 signaling pathway played a protective role. SIRT1 overexpression in these cells, induced by transfecting with a SIRT1 overexpression vector, led to a substantial increase in Nrf2 protein expression and activity, which in consequence upregulated the expression of Nrf2 downstream genes such as superoxide dismutase, glutation, catalase and heme oxygenase-1. The effect was inhibition of cell apoptosis. SIRT1 downregulation by transfecting it with SIRT1-targeting shRNA induced the production of malondialdehyde, which resulted in increased oxidative damage [75]. A group from P. Barnes laboratory [76] have analyzed the effects of sirtuin inhibition using sirtinol (a non-specific sirtuin inhibitor) on Nrf2 protein levels as well as its activity after stimulation with $\mathrm{H}_{2} \mathrm{O}_{2}$. Results show that increases in Nrf2 stability are not controlled by sirtuins but by class I and II histone deacetylases. A new study reported that SIRT2 deacetylates lysines 506 and 508 residues of Nrf2, resulting in a decrease in both total cellular and nuclear levels of Nrf2 (through its degradation). The diminution in nuclear Nrf2 is associated with a reduction in its transcription of the target gene Fpn1 [77]. Conversely, it has been shown on PC12 neuroblastoma cells that SIRT2 may positively regulate nuclear Nrf2 expression by modulating Akt phosphorylation. Additionally it was prevented by both SIRT2 siRNA and SIRT2 inhibitor-AGK2. SIRT2 siRNA also blocked the NADH-induced increases in glutamate cysteine ligase (GCL) and glutathione [78]. Another study on PC12 neuroblastoma cells showed that silencing can virtually abolish 
the effects of NAD ${ }^{+}$on the Nrf2 activity. Moreover, the SIRT2 inhibitor AGK2 treatment attenuated the increases in the Nrf2 mRNA levels and the nuclear Nrf2 levels induced by $\mathrm{NAD}^{+}[24,79]$. McDougald et al. [80] have interrogated the impact of SIRT1 or Nrf2 overexpression in experimental optic neuritis via adeno-associated virus gene transfer to retinal ganglion cells. Authors have examined whether the SIRT1 or Nrf2 gene augment the suppression of retinal ganglion cell death, optic nerve inflammation, and demyelination in a mouse model of multiple sclerosis. Transfection with the SIRT1 gene results in a positive trend in retinal ganglion cell survival. The Nrf2 gene transfer provided the most robust protective response with respect to total and regional retinal ganglion cell survival. There is also a study showing that SIRT1 deacetylated and reduced the ubiquitination level of Nrf2 in Sprague Dawley rat primary glomerular mesangial cells challenged with advanced glycation-end products. It also promoted Keap1/Nrf2/ARE anti-oxidative pathway activation, which exerts crucial inhibitory effects on the development of diabetic nephropathy, leading to a reduction in fibronectin and TGF- $\beta 1$ levels. The diminution of Nrf2 blocked those effects of SIRT1. Interestingly, Nrf2 also positively regulated SIRT1 at the levels of protein expression and deacetylase activity [81].

It can be seen that the SIRT/Nrf2 pathway can antagonize oxidative damage by enhancing the cells' antioxidant capacity. Further research is needed to clarify whether the regulation of Nrf2 may also have significant effects on defense mechanisms against oxidative stress, as Nrf2 is activated by oxidative stress and plays a crucial role in the transcriptional activation of the defense machinery. The above mentioned effect of SIRT on Nrf2 action is presented on Figure 2.

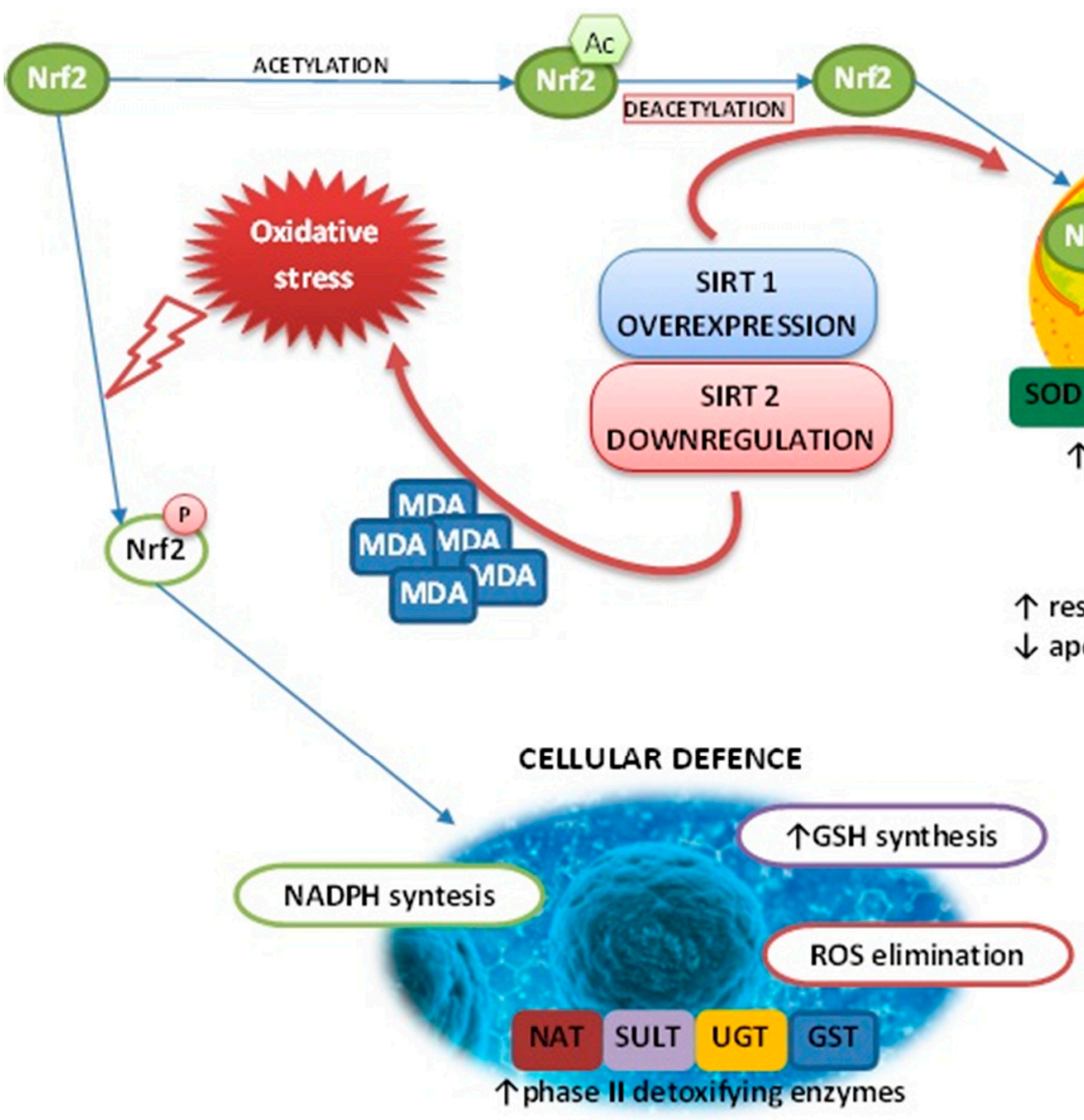

Figure 2. Schematic representation of the effect of SIRTs on Nrf2 metabolism. GSH-glutathione; GST—glutathione S-transferase; UGT-UDP-glucuronosyltransferase; NAT—N-acetyltransferase; SULT—sulfotransferase; SOD—superoxide dismutase; CAT—catalase; HMOX1—heme oxygenase-1; MDA—malondialdehyde. 


\subsection{The Sirtuin-NF- $\kappa B$ Interaction}

Despite the somewhat misleading 'histone deacetylase' term, SIRTs amend a broad range of non-histone proteins and transcription factors including those responsible for anti-inflammatory response such as nuclear factor kappa-light-chain-enhancer of activated $B$ cells (NF- $\mathrm{kB}$ ). The NF- $\mathrm{kB}$ pathway has been proposed to be an universal promoter of the innate immunity and inflammatory response, as well as its activity plays a significant role in boosting neurodegeneration processes, ischemia and other diseases [82]. Overexpression of SIRT1 deacetylase and the addition of resveratrol blocked NF- $\mathrm{kB}$-dependent gene transactivation stimulated by amyloid $\beta(A \beta)$ and had strong neuroprotective effects in microglia BV2 and primary neuronal culture isolated from Sprague-Dawley rat pups [83]. The modulation of senescence via NF- $\mathrm{KB}$ is possible due to its interactions with SIRTs. While, overactive NF- $\kappa B$ signaling may lead to premature aging it was shown that SIRT6 tempers this process via deacetylation of histone $\mathrm{H} 3$ lysine 9 at NF- $\mathrm{kB}$ target gene promoter [84]. Despite vast spectrum of cellular mechanism and intracellular localizations (shown in Figure 3), most SIRTs inhibits NF-kB activity.

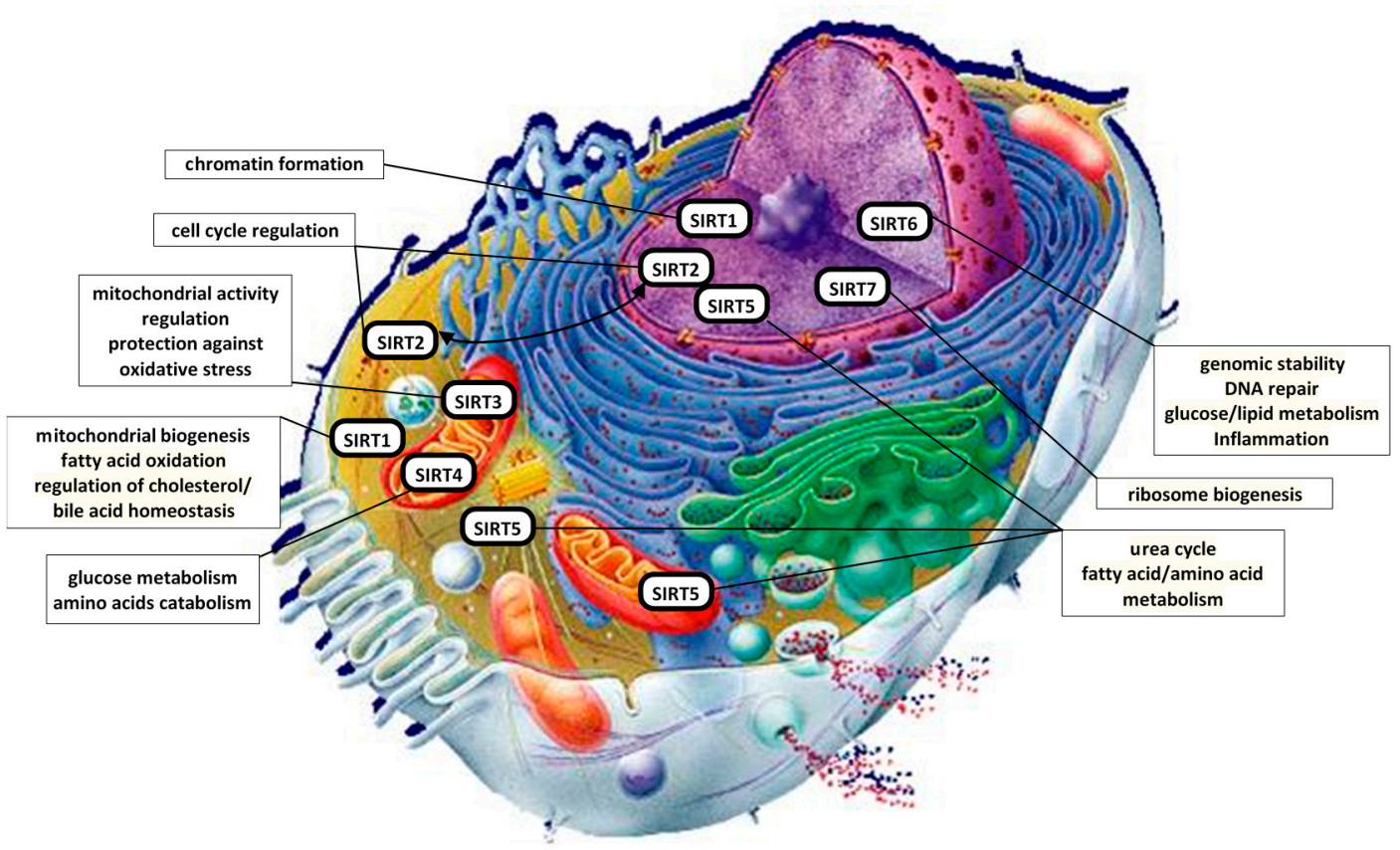

Figure 3. Cellular localization and main cellular mechanisms in which SIRTs participate [82].

For example, SIRT1 and SIRT6 deacetylates RelA subunit of NF-kB, repressing its target promoters inhibiting apoptosis and cellular senescence $[84,85]$. SIRT1 also interacts with NF-KB's transcriptional corepressor- transducin-like enhancer of split-1 (TLE-1) and deacetylates lysine 310 on p65 protein leading to diminution of NF- $\mathrm{KB}$ activity $[86,87]$ SIRT3 - a transcriptional target of NF- $\mathrm{kB}$, was shown to regulate inhibitory effect of metformin on NF-kB activity in differentiated L6 skeletal muscle cells with induced insulin resistance [88]. In cigarette smoke extract (CSE)-treated human pulmonary microvascular endothelial cells overexpression of SIRT4 blocks the degradation of inhibitor of NF- $\mathrm{kB}$ and in consequence downregulated CSE-induced NF-kB activation [89]. Moreover, SIRT4 mitigated nuclear translocation and transcriptional activity of NF- $\kappa B$ in human umbilical vein endothelial cells suppressing endothelial inflammation processes [90]. SIRTs thus concurrently influence the pro-inflammatory and possibly toxic activities of NF- $\mathrm{kB}$ and modulates the stress resistance signals of insulin/IGF-I signaling [82,91]. Furthermore, SIRT1 also interact with an important partner of p53 protein and NF- $\mathrm{kB}-\mathrm{p} 300$ by inhibiting its acetylating activity [92]. Protein p300 is a transcriptional co-activator which role is to arrest the interaction of histones with DNA through their acetylation. However, the impact 
of SIRT2 on p300 seems to be contrary to that of SIRT1. It deacetylates lysine residues in the catalytic domain of p300 leading to inhibition of transcription. Nicotinamide, a competitive inhibitor by product of the SIRT deacetylation reaction, was sufficient to prevent deacetylation of acetylated p300 [93]. In turn, p300 inhibits SIRT2 through acetylation, attenuating its negative influence on p53 protein [94]. The influence of different SIRTs on p300 and NF- $\mathrm{kB}$ activity is not fully determined. The measurement of selected SIRTs substrates in vivo such as, e.g., p53 or NF- $\mathrm{kB}$, and other, remains an important tool for evaluating changes in SIRTs activity and give more light and understanding to complex processes in which SIRTs are involved.

\section{Sirtuins in Selected Pathological States}

The wide spectrum of interactions and the multitude of cellular processes in which SIRTs take part, combined with the fact that disturbances in their expression and/or activity are observed in many pathological conditions occurring in the human body, point to the conclusion that SIRTs play a beneficial role in physiological states. Research on the influence of SIRTs as well as the level of their expression in homeostasis disturbances was made through clinical testing on animal models and in vitro cell cultures. A close relationship has been demonstrated between the degree of expression of SIRTs and diseases affecting many various internal organs [95-102]. The enzymatic activity of SIRTs on selected organs is schematically shown in Figure 4.

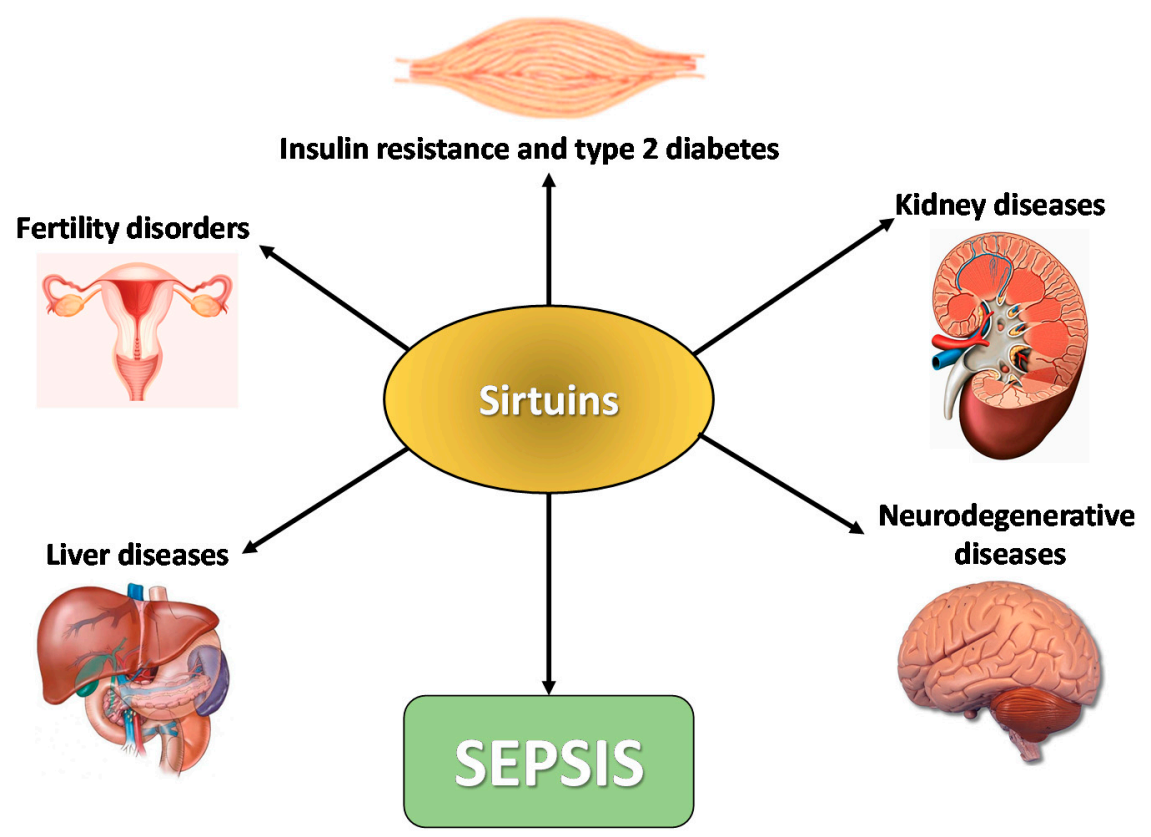

Figure 4. The enzymatic effect of SIRTs on selected organs. Modification according to Giblin et al. [103].

It has been proven that the degree of SIRTs expression varies depending on the type of abnormality in the body and the organ affected, as detailed in Table 2. 
Table 2. Participation of SIRTs in selected pathological disorders.

Sirtuins

Enzymatic Activity

SIRT1

$\mathrm{NAD}^{+}$-dependent deacetylase
$\mathrm{NAD}^{+}$-dependent deacetylase
Function [10]

formation of facultative and constitutive chromatin mitochondrial biogenesis

fatty acid oxidation

regulation of cholesterol and bile acid homeostasis
Participation in Selected Pathological Conditions

Increased expression:

acute myeloid leukemia [104]

chronic myeloid leukemia [105]

cancer:

stomach, colon $[106,107]$

prostate [108]

ovary, breast $[109,110$

melanoma [111]

lungs [112]

glioblastoma [113]

Decreased expression:

colon cancer [114]

neurodegenerative diseases $[17,25,97,115,116]$

cardiovascular diseases [25]

\section{Increased expression:}

acute myeloid leukemia [117]

prostate cancer [118]

chronic myeloid leukemia [105]

cell cycle regulation

promoting lipolysis in adipocytes

tumor suppression/promotion

neurodegeneration neurodegenerative diseases $[17,25]$

Decreased expression:

breast cancer [119]

skin cancers [120]

skin tumor [121]

glioblastoma [122]

cardiovascular diseases [25] 
Table 2. Cont.

\begin{tabular}{|c|c|c|c|}
\hline Sirtuins & Enzymatic Activity & Function [10] & Participation in Selected Pathological Conditions \\
\hline SIRT3 & $\mathrm{NAD}^{+}$-dependent deacetylase & $\begin{array}{l}\text { regulation of mitochondrial activity } \\
\text { protection against oxidative stress } \\
\text { tumor suppression }\end{array}$ & $\begin{array}{l}\text { Increased expression: } \\
\text { colon cancer [123] } \\
\text { stomach cancer [124] } \\
\text { Decreased expression: } \\
\text { breast cancer [125] } \\
\text { liver cancer [126,127] } \\
\text { pancreatic cancer [128] } \\
\text { chronic lymphocytic leukemia [129] } \\
\text { female fertility disturbances [19] } \\
\text { type } 2 \text { diabetes [16] } \\
\text { neurodegenerative diseases [25,102] } \\
\text { cardiovascular diseases [25] }\end{array}$ \\
\hline SIRT4 & ADP-ribosyltransferase & $\begin{array}{l}\text { glucose metabolism } \\
\text { catabolism of amino acids } \\
\text { tumor suppression }\end{array}$ & $\begin{array}{l}\text { Increased expression: } \\
\text { esophageal cancer [130] } \\
\text { breast cancer [131] } \\
\text { thyroid cancer [132] } \\
\text { myocardial hypertrophy [133] } \\
\text { Decreased expression: } \\
\text { stomach cancer [134,135] } \\
\text { colon cancer [135,136] } \\
\text { liver cancer [135] } \\
\text { endometrial carcinoma [137] } \\
\text { esophageal cancer [138] }\end{array}$ \\
\hline SIRT5 & $\begin{array}{l}\mathrm{NAD}^{+} \text {-dependent deacetylase } \\
\text { demalonylase } \\
\text { desuccinylase }\end{array}$ & $\begin{array}{l}\text { urea cycle } \\
\text { fatty acid metabolism } \\
\text { amino acid metabolism }\end{array}$ & $\begin{array}{l}\text { Increased expression: } \\
\text { non-small cell lung cancer [139] } \\
\text { colorectal cancer [140,141] } \\
\text { liver cancer [142] } \\
\text { ovarian cancer [143] } \\
\text { breast cancer [144] } \\
\text { neurodegenerative diseases [25] }\end{array}$ \\
\hline
\end{tabular}


Table 2. Cont.

Sirtuins

$\mathrm{NAD}^{+}$-dependent deacetylase

ADP-rybozylotransferase

genomic stability/DNA repair

glucose and lipid metabolism

inflammation
Function [10]
Participation in Selected Pathological Conditions

Increased expression:

multiple myeloma [145]

acute myeloid leukemia [146]

squamous cell carcinoma [120,147]

liver cancer $[148,149]$

prostate cancer $[150,151]$

Decreased expression:

colorectal cancer [152-154]

breast cancer $[155,156]$

liver cancer [98]

bladder and prostate cancer [151]

ovarian cancer [157]

pancreatic cancer [158]

neurodegenerative diseases [25]

cardiovascular diseases [25]

heart failure [159]

cardiac fibrosis [160]

Increased expression:

breast cancer [161]

thyroid cancer $[161,162]$

stomach cancer [151]

colorectal cancer [151]

prostate cancer [163]

liver cancer [164]

Decreased expression:

pancreatic cancer $[128,165]$ 
Increased expression of SIRTs can both promote the development of the disease and inhibit the progress of the pathological process in the body. In some disease states, an appropriate level of SIRTs expression may support treatment as well as be a prognostic factor in the ongoing disease process $[109,112,114,118,132,138,148,165]$. On the other hand, there is ample evidence that the levels of expression of a given sirtuin may be increased or decreased in the same pathology, which indicates a possible dual role for these proteins. For example, SIRT2 deficiency or inhibition with AGK2 appears to be protective mainly against acute liver injury and, conversely, SIRT2 overexpression aggravated liver damage, what suggest that SIRT2 exerts both protective and aggravating roles in cardiometabolic disorders, and its activation or inhibition depends on type and context of disorders [25]. Sirtuins play an important role in the post-translational modification of proteins. They cause changes in the chromatin structure, influencing the degree of acetylation/deacetylation of histones by direct participation in acetylation and deacetylation of lysine molecules present in histones. They can also change the activity of transcription factors and regulatory proteins, which additionally modulates changes in chromatin and affects the course of many processes in the cell, and thus the functioning of the organism. Sirtuins take part not only in post-translational modifications of proteins, but also in compensation mechanisms triggered in response to adverse environmental conditions and participate in epigenetic modifications that cause the development of many diseases, including type 2 diabetes, obstructive pulmonary disease, neoplastic, neurodegenerative or cardiovascular diseases as well $[15,22,25]$. Due to the fact that epigenetics is a rapidly developing branch of modern molecular biology, the epigenetic aspect of sirtuins action seems to be interesting, especially in the context of the role that sirtuins play in the pathogenesis of many diseases. Epigenetic changes include acquired and heritable chromatin modifications that regulate the expression and function of genes without affecting the DNA sequence, processes that perfectly match sirtuins. Sirtuins, apart from regulating the degree of histone acetylation by acting on various target substrates, are also involved in the regulation of the cell cycle, energy metabolism, the process of cell differentiation, apoptosis and cellular response to stress (e.g., oxidative, energetic or induced by ultraviolet radiation) [166-168]. Figure 5 shows how SIRTs activity affects cell proliferation, apoptosis and tumorigenesis. 


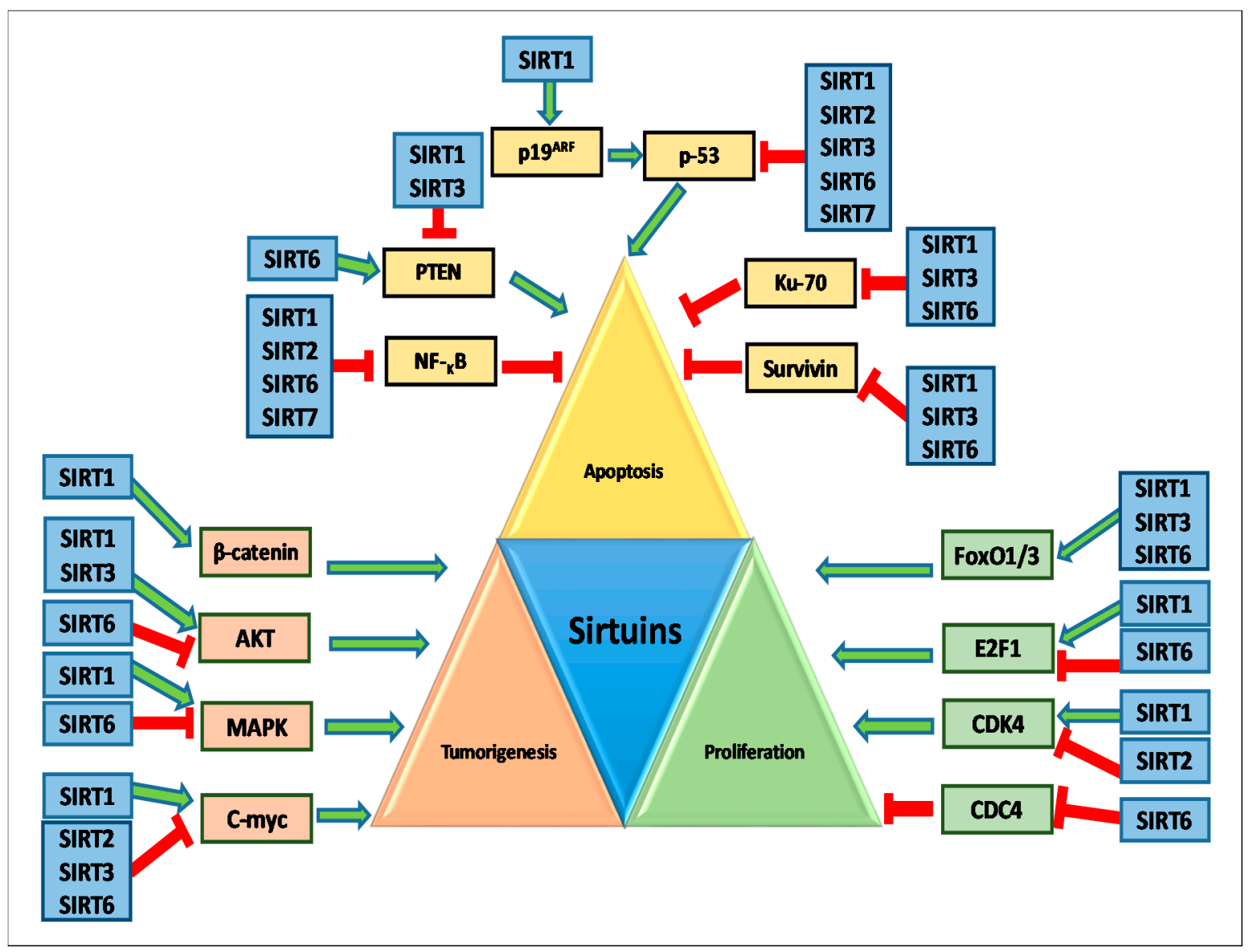

Figure 5. Role of SIRTs in cell proliferation, apoptosis, and tumorigenesis. AKT-protein kinase B; CDC4-cell division control protein 4; CDK4-cyclin-dependent kinase 4; C-myc-transcription factor; E2F1-transcription factor E2F1; FoxO1/3forkhead family of transcription factors; Ku70-protein Ku; MAPK mitogen-activated protein kinase; NF- $\mathrm{B}$-transcription nuclear factor $\mathrm{kB}$; PTEN-phosphatase and tensin homolog deleted on chromosome Ten; p19ARF-ARF tumor suppressor; p-53-protein 53; Survivin-baculoviral inhibitor of apoptosis; SIRT1-7-sirtuins 1-7; $\beta$-catenin-dual function protein; -_inhibitory effect, $\Longrightarrow$ _activating effect. Modification based on Zhao et al. [169].

\section{Modulating Sirtuins Activity}

Modulating the activity of sirtuins due to the multidirectional action of these deacetylases has also been the subject of numerous studies. Both activators and inhibitors of these enzymes can be divided into substances of natural origin (e.g., activator-resveratrol) and synthetic substances (e.g., inhibitor-MC3482). Sirtuin activators or inhibitors, i.e., compounds that either increase/decrease the rate of the enzymatic reaction or increase/decrease the affinity of the enzyme for the substrate, respectively, are becoming the object of increasing interest of many research teams due to their various functions described in Table 3 [25,170,171]. Since no activators or inhibitors are known for SIRT7 so far, it is not included in the table. 
Table 3. The most important known SIRT modulators.

\begin{tabular}{|c|c|c|}
\hline Human Sirtuins & Activators & Inhibitors \\
\hline SIRT1 & $\begin{array}{l}\text { curcumin [44] } \\
\text { quercetin }[172] \\
\text { luteolin }[173] \\
\text { resveratrol }[7,174] \\
\text { SRT1720 [175] }\end{array}$ & $\begin{array}{l}\text { cambinol [7] } \\
\text { nicotinamide [176] } \\
\text { salermide [7] } \\
\text { selisistat [7] } \\
\text { sirtinol [177] } \\
\text { tenovin-1 [178] } \\
\text { tenovin-6 [178] }\end{array}$ \\
\hline SIRT2 & resveratrol [179] & $\begin{array}{l}\text { cambinol [7] } \\
\text { salermide [7] } \\
\text { selisistat [170] } \\
\text { sirtinol [180] } \\
\text { SirReal2 [181] } \\
\text { tenovin-1 [178] } \\
\text { tenovin-6 [178] } \\
\text { quercetin [182] }\end{array}$ \\
\hline SIRT3 & $\begin{array}{l}\text { curcumin [170] } \\
\text { honokiol [170] } \\
\text { luteolin [173] } \\
\text { resveratrol [170] }\end{array}$ & selisistat [170] \\
\hline SIRT4 & $\begin{array}{l}\text { curcumin [170] } \\
\text { resveratrol [170] }\end{array}$ & unknown \\
\hline SIRT5 & resveratrol [174] & $\begin{array}{l}\text { cambinol [170] } \\
\text { MC3482 [183] } \\
\text { suramin [7] }\end{array}$ \\
\hline SIRT6 & $\begin{array}{l}\text { cyanidin [184] } \\
\text { quercetin [184] } \\
\text { luteolin [184] }\end{array}$ & $\begin{array}{l}\text { catechin [170] } \\
\text { SirReal2 [170] }\end{array}$ \\
\hline
\end{tabular}

\subsection{The Most Important SIRT Activators}

\subsubsection{Cyanidin}

Cyanidin is the major component of anthocyanins, commonly found in the Mediterranean diet. It is most abundant in red berries including bilberry, raspberry and cranberry. It has been documented that cyanidin exhibits anti-inflammatory effects in a variety of diseases [184]. Some authors $[185,186]$ have suggested that anthocyanidins, including cyanidin, may play important roles in helping to reduce the risk of many age-related diseases. Cell culture and in vivo studies of anthocyanidins and their glycosylated counterparts (anthocyanins) revealed anticarcinogenic properties against colon, skin and lung cancer $[185,186]$. Studies by Cho at al. [187] on mice showed that mulberry cyanidin-3glucoside inhibit the tumor proliferation and growth in the in vitro and in vivo model, indicating the inhibition of tumor progression [187]. Studies in a variety of cancer cells revealed that anthocyanins activate detoxifying enzymes, prevent cancer cell proliferation, induce cancer cell apoptosis, and have anti-inflammatory and antiangiogenic effects $[185,186]$. Cyanidin affected the expression of SIRT6-associated genes such as FoxO3 $\alpha$, Twist1 and GLUT1. FoxO3 $\alpha$ belongs to the family of forkhead box transcription factors that plays an important role in regulating the expression of genes involved in cell growth, proliferation, differentiation and longevity. The deregulation of $\mathrm{FoxO} 3$ is involved in tumorigenesis. Previous studies reported that the FoxO3 $\alpha$ gene is regulated by SIRT6, which forms a complex with FoxO3 $\alpha$ in the nucleus and further induces the expression of genes involved in antioxidation [188].

\subsubsection{Curcumin}

Curcumin is a phenolic compound extracted from the natural herb turmeric. It is obtained from turmeric rhizomes (Curcuma longa L.) and exists in two isoforms: ketone 
and enol. It is poorly absorbed in the small intestine, from where it is transported to the liver and then degraded [189]. Studies by Hu et al. [190] conducted on cell cultures showed that an increase in SIRT1 expression was observed in neoplastic cells (squamous cell carcinoma of the head and neck, FaDu and Cal27 cells) that were treated with curcumin. This activating effect was cancelled after preincubation with nicotinamide- the inhibitor of this deacetylase. Moreover, a decrease in the degree of acetylation of the lysine residues of the p53 protein, which is a substrate for SIRT1, was demonstrated, confirming the positive effect of curcumin on the activity of this sirtuin. It has also been shown that SIRT1 inhibit the expression of the NF- $\mathrm{KB}$ factor and proliferation of neoplastic cells, as evidenced by the reduced expression of the Ki-67 marker. The research of Sahin et al. [191] confirms that an increase in the expression of SIRT1 and the coactivator- $1 \alpha$ for the peroxisome proliferator-activated $\gamma$ receptor (PGC1 $\alpha$ ) was observed in skeletal muscle cells of rats that were fed curcumin. In studies carried out on mice with myocardial damage, it was reported that curcumin reduces the intensity of myocardial fibrosis by activating SIRT1 through a mechanism dependent on this deacetylase [192]. This activator also influences lipid metabolism. The action of curcumin increases the concentration of the mRNA of ATP-binding cassette transporter protein (ABCA1), which is responsible for the transportation of excess cholesterol and phospholipids to macrophage-derived foam cells. A similar relationship was observed for the liver $X$ receptor $\alpha(\operatorname{LXR} \alpha)$, suggesting that this receptor protein controls $\mathrm{ABCA} 1$ expression. It has been proven that the expression of AMP-activated protein kinase (AMPK) and SIRT1 increases in foam cells treated with curcumin [193]. Lin et al. [193] also showed that curcumin increases cholesterol efflux by increasing ABCA1 expression as a result of activating AMPK-SIRT1-LXR $\alpha$ signaling in foam cells derived from THP-1 macrophages. Moreover, after preincubation with an AMPK inhibitor, a decrease in the expression of $L X R \alpha, A B C A 1$ and SIRT1 was observed in these cells. This indicates that ABCA1 expression is dependent on the interaction of these compounds, which in turn is controlled by the action of curcumin [193]. Curcumin can also activate the PGC1 $\alpha /$ SIRT3 signaling pathway to protect against mitochondrial impairment, and it can stimulate SIRT1 to have cardioprotective effects [192].

\subsubsection{Honokiol}

Honokiol (HKL), a small molecular weight polyphenol, is an activator of SIRT3. HKL is derived from the magnolia tree. HKL's anti-cancer activity has been studied extensively and it was found to be effective in several animal models of cancer, including lung, prostate, breast, colon and pancreatic cancers [194,195]. Besides its cytotoxicity in cancer, HKL was reported to induce a variety of cytoprotective activities, including anti-inflammatory, anti-thrombotic, anti-arrhythmic, neuroprotective, anti-oxidative, and anti-hypertrophic effects. Thus, HKL has the potential to act both as an antitumor and cytoprotective molecule $[196,197]$.

\subsubsection{Luteolin}

Luteolin ( $3^{\prime}, 4^{\prime}, 5,7$-tetrahydroxylflavone), a natural flavonoid found in fruits, vegetables, and medicinal herbs, also exerts anti-inflammatory, anti-allergic, anti-cancer, antioxidant and other beneficial health effects [198]. Luteolin is also known to improve blood glucose, HbA1c, insulin levels and fatty acid metabolism-related gene expression [199]. Kim et al. [173] observed that SIRT1, SIRT3, SIRT6 and FoxO3a expression was decreased in hyperglycemia-induced monocytes. Conversely, the downregulated expressions of SIRT1, SIRT3, SIRT6 and FoxO3a were restored to levels similar to normoglycemic conditions by luteolin treatments. Luteolin treatments modulate SIRT1, SIRT3 and SIRT6 expressions under hyperglycemics conditions [173].

\subsubsection{Resveratrol}

Resveratrol (RSV, 3,5,4'-trihydroxy-trans-stilbene) is a naturally occurring flavonoid that, due to its chemical structure, belongs to stilbens. It occurs in two optical isoforms: 
cis and trans, only the latter of which occurs naturally and is biologically active. Due to its protective effect, it is a natural phytoalexin, and is synthesized by plants in response to infections, structural damage, oxidative stress and excessive UV radiation. It occurs naturally in many plants and its highest concentration was found in the root of knotweed (Reynoutria japonica) as well as in various types of red wines, due to its presence in the skins of red grapes. It's also present in lower concentrations in peanuts, berries, cranberries, strawberries, white hellebore, scots pine, rhubarb, orchids, tomatoes and cocoa. In humans, it is absorbed in the small intestine and metabolized in the liver, with both reactions catalyzed by cytochrome P450 enzymes [200,201].

RSV has been shown to be the primary natural activator of SIRT1. Using the Fluor de Lys kit (BioMol, Hamburg, Germany), Borra et al. [202] demonstrated the ability of RSV to cause an 8-fold increase in the activity of SIRT1, which was not detected for SIRT2. Moreover, it was observed that although SIRT1 stimulation was independent of acetylpeptide sequence, RSV activation was also related to the presence of a covalently attached fluorophore. Other fluorophore-containing media was shown to bind more closely to SIRT1 in the presence of RSV. RSV interacts with SIRT1 in allosteric activation. This compound activates SIRT1 through tree subunits-Res1, Res2 and Res3. These subunits act on SIRT1 to increase its ability to bind to the p53 protein. The activating properties of RSV are related to its interaction with the N-terminal part of the SIRT1 chain, and SIRT1 molecules lacking this fragment are not activated. The Res1 and Res 2 subunits interact with both the N-terminal portion of the SIRT1 domain and its methylcoumarin substrate (p53-AMC) by forming hydrogen bonds. Res3, on the other hand, binds to the catalytic domain of deacetylase. Subsequently, the p53-AMC substrate is bounded by deacetylase at the site between the N- and C-terminus of SIRT1, and resveratrol enhances this interaction. Moreover, the presence of the glutamic acid residue located at position 230 (Glu230) has been shown to be important for the activation capacity of RSV. Lower activity of RSV is connected with conversion from glutamic acid to a lysine or alanine residue. Glu230 also interacts with an arginine residue located at position 446, present in the SIRT5 catalytic domain, resulting in an increase in the ability to activate this deacetylase [203,204]. Mancuso et al. [205] on SOD1G93A model of amyotrophic lateral sclerosis (ALS) mice revealed promising neuroprotective effects of RSV since it induces expression and activation of several neuroprotective pathways involving SIRT1 and AMPK in the ventral spinal cord. Their results demonstrate that microglial, but not astroglial reactivity, was significantly diminished with resveratrol administration compared to untreated SOD1G93A mice [205].

Studies by Pan et al. [179] demonstrated that resveratrol activates SIRT2 to deacetylate Prx1-27AcK, which significantly enhances its $\mathrm{H}_{2} \mathrm{O}_{2}$-reducing activity in HepG2 cells when using purified enzymes and/or substrates. The key role of $\mathrm{H}_{2} \mathrm{O}_{2}$ in carcinogenesis is supported by the tendency of cancer cells to have an elevated level of $\mathrm{H}_{2} \mathrm{O}_{2}$, which may play a key role in malignant transformation and explains many hallmarks of cancer, such as DNA damage and genetic instability. Conversely, an increase in $\mathrm{H}_{2} \mathrm{O}_{2}$-detoxifying enzyme activity can reduce the rate of cell proliferation and inhibit cancer metastasis [206]. Pan et al. [179] showed that small molecules targeting SIRT2 and Prx1 may modulate intracellular redox status in the therapeutic strategies for disorders related to aging. Whereas the studies of Eren et al. [207] revealed that resveratrol treatment induces premature senescence in human dermal fibroblasts, which is mediated by DNA damage and by the activation of p53-p21and Rb-p16 pathways. More importantly, concomitant decline in levels of SIRT1 and SIRT2 upon resveratrol treatment may be a cause for the induction of senescence, which is most likely mediated by a regulatory mechanism activated by DNA damage response [207]. Resveratrol is a polyphenol that has neuroprotective effects against many neurological disorders. This is confirmed by a study by Yan et al. [208], which investigated the potential protective effects of resveratrol in an in vitro ER stress model mimicked by tunicamycin treatment in neuronal HT22 cells. Authors reported that resveratrol exerts protective effects against tunicamycin-induced ER stress by regulating SIRT3-mediated autophagy in neuronal HT22 cells. These findings may reveal a new feature for the mech- 
anism of resveratrol in neuroprotection, and provide further information regarding the role of SIRT3 in autophagy regulation [208]. SIRT5 can be activated by resveratrol and piceatannol (a resveratrol metabolite that carries an additional hydroxyl group), with a potency comparable to that reported for SIRT1 [209].

\subsubsection{SRT1720}

SRT1720 is a synthetically produced chemical compound that belongs to polyphenols and is a derivative of RSV. It interacts with the catalytic domain of the enzyme, which reduces its activation energy for acetylated substrates and acts as an activator of this deacetylase. Although it significantly differs from RSV in molecular structure, it binds SIRT1 at the same target site and interacts with it through allosteric activation. It has been shown that SRT1720 binds to the SIRT1 substrate-peptide complex at the amino terminus of the catalytic domain and lowers the Michaelis constant for acetylated substrates. In addition, it has a much greater efficiency of SIRT1 activation (about 1000 times stronger than RSV) $[175,210]$. The ability to increase the catalytic activity of SIRT1 by SRT1720 was demonstrated by Chauhan et al. [211]. Studies conducted on multiple myeloma cells indicated an increase in apoptosis induced by the activation of caspases 8 and 9 as well as inhibition of the expression of another SIRT1 substrate-the NF- $\mathrm{kB}$ factor. The action of SRT1720 on myeloma cells also increases the concentration of ATM kinase (ataxiatelangiectasia mutated kinase) and increases its ability to interact with the effector kinase involved in DNA repair - checkpoint kinase 2 (CHEK2) — which leads to cell death induced by this complex. This activator inhibits the growth of multiple myeloma cells, as confirmed through in vivo studies by lowering the expression of the Ki-67 marker-an indicator of the cell's ability to proliferate. It has been reported that, in Zucker rats (fa/fa type), by affecting SIRT1, this activator decreased the fasting glucose concentration and improved the insulin sensitivity of cells [210]. Administration of SRT1720 reduces the degree of acetylation of one of the substrates for sirtuin 1-PGC1 $\alpha$ without affecting the concentration of this deacetylase in cells. As a consequence, decreased lipid storage in mouse liver cells, decreased aspartate aminotransferase activity, and the expression of genes of other enzymes involved in lipid metabolism, such as sterol regulatory element-binding protein 1 (SREBP-1c) and PGC1 $\alpha$, was observed. In the hepatocytes of mice treated with SRT1720, fat synthesis was decreased and lower concentration of free fatty acids, triglycerides and cholesterol was also noted [212].

\subsubsection{Quercetin}

Quercetin $\left(5,7,3^{\prime}, 4^{\prime}\right.$-flavon-3-ol), is an organic polycyclic compound that belongs to flavonoids, the most abundant group in the world of plants. It belongs to the class of flavonols (3,4-diols flavan). It occurs, among others, in tea, fruit (apples, dark grapes, black currant, chokeberry), vegetables (e.g., onion, broccoli), herbs such as horsetail and St. John's wort, and the flowers of e.g., hawthorn [213]. Due to its chemical structure, it belongs to the group of glycosides (e.g., rutin and rutoside), but it can also be present in free form as an aglycone. It is formed in a multistage reaction pathway from L-phenylalanine [214]. In the form of an aglycone, it is absorbed in the entire intestine, while glycosides can only be absorbed in the large intestine, where they undergo changes under the influence of enzymes produced by present bacteria [213]. It has been shown that short-term administration (7 days) of quercetin $(12.5 \mathrm{mg} / \mathrm{kg}$ or $25 \mathrm{mg} / \mathrm{kg})$ to mice results in an increase of the concentration of PGC1 $\alpha$ mRNA and SIRT1, the expression of mtDNA, and cytochrome $\mathrm{C}$ concentration in skeletal muscle cells and in mice brains [172]. Moreover, it has been proved that administration of this compound to mice fed a high-fat diet for 12 weeks influenced not only the parameters of lipid and carbohydrate metabolism, but also inhibited the infiltration of macrophages into adipose tissue and suppressed the inflammatory process by acting on the AMPK $\alpha 1 /$ SIRT1 pathway [215]. In rats with streptozotocin-induced diabetes, after 12 weeks of administration of low or high doses of quercetin $(10 \mathrm{mg} / \mathrm{kg}$ and $50 \mathrm{mg} / \mathrm{kg}$, respectively), there was an improvement in lipid and carbohydrate metabolism 
parameters, the expression and hepatic activity of SIRT1 were increased, and the serine/threonine (Akt) protein kinase signaling pathway was activated by phosphorylation and deacetylation. This indicates that the beneficial effect of quercetin on the disturbance of glucose and lipid metabolism is probably related to the increased activity and concentration of the SIRT1 protein and its influence on the Akt signaling pathway [216]. Studies by Kamelo et al. [217] have shown that in liver cells of rats subjected to cytotoxic action of Dgalactosamine/lipopolysaccharide complex (D-GalN/LPS), administration of this activator increased the expression of SIRT1 to a greater degree than observed after administration of its synthetic analogue-SRT1720, as evidenced by lower levels of liver damage markers (aminotransferases and bilirubin).

Quercetin has been shown to modulate SIRT6 in addition to SIRT1. Two quercetin derivatives, diquercetin and 2-chloro-1,4-naphthoquinone-quercetin, have been identified as promising SIRT6 inhibitors. 2-Chloro-1,4-naphtoquinone-quercetin also showed potent inhibition against SIRT2. Diquercetin increased the $\mathrm{Km}$ value of $\mathrm{NAD}^{+}$, whereas 2-chloro1,4-naphthoquinone-quercetin increased the value of the acetylated substrate. Molecular docking studies suggest that diquercetin prefers the binding site of the nicotinamide (NAM) moiety, whereas 2-chloro-1,4-naphtoquinone-quercetin prefers to dock into the substrate binding site. The results of in vitro studies and molecular modelling indicated that diquercetin competes with nicotinamide adenine dinucleotide $\left(\mathrm{NAD}^{+}\right)$, whereas 2-chloro1,4-naphthoquinone-quercetin competes with the acetylated substrate in the catalytic site of SIRT6 [182].

\subsection{The Most Important Sirtuin Inhibitors}

\subsubsection{Cambinol}

Cambinol inhibits $\mathrm{NAD}^{+}$-dependent deacetylase activity of human SIRT1 and SIRT2. It has weak inhibition against SIRT5 and no inhibition against SIRT3. Consistent with the role of SIRT1 in promoting cell survival during stress, inhibition of SIRT1 activity with cambinol during genotoxic stress leads to hyperacetylation of key stress response proteins and promotes cell cycle arrest. Cambinol exerts antitumor activity in vitro and in mouse xenograft studies [184]. Cambinol markedly decreases aromatase levels in human breast cancer cells by inhibiting SIRT1-mediated deacetylation and transcription activity of estrogen-related receptor $\alpha[218,219]$.

\subsubsection{Catechin}

Catechin is a flavan-3-ol, a type of natural phenol and antioxidant. It belongs to the group of plant flavanols, which is part of the chemical family of flavonoids. Flavonoids are polyphenolic secondary metabolites synthesized by plants and fungus with various pharmacological effects [220]. Catechins hit multiple targets in cancer therapy and are also found to be useful in man-aging multidrug-resistant tumors. They have been shown to suppress several key pathways linked to oncogenesis, including those involved in cell survival, proliferation, and invasion, along with angiogenesis. They are also helpful against disorders involving lipid and glucose metabolism, such as type 2 diabetes and obesity, and could alleviate the risk of cardiovascular diseases [220]. Catechins have been shown to modulate the activity of a NAD ${ }^{+}$-dependent histone deacetylase, SIRT6. In the study by Rahnasto-Rilla et al. [184], catechins exhibited inhibition activity against SIRT6-catalyzed H3K9Ac deacetylation.

\subsection{3. МC3482}

MC3482 is a synthetic sirtuin inhibitor that is effective in inhibiting SIRT5. After the application of this inhibitor, Polletta et al. [183] observed an increase in ammonia concentration in cells with a similar intensity as in cells with silenced expression of the SIRT5 gene. SIRT5 participates in the transformation of ammonia in the urea cycle by regulating carbamoyl phosphate synthetase I in liver and kidney cells [183]. 


\subsubsection{Nicotinamide}

Nicotinamide (nicotinic acid amide) is formed as a product of $\mathrm{NAD}^{+}$transformations under the influence of enzymes (e.g. SIRTs), nicotinamide nucleoside phosphorylase, or nicotinamide phosphoribosyltransferase. The products of nicotinamide metabolism in the body are nicotinamide N-oxide or N-methylnicotinamide [221]. Nicotinamide has been found to non-competitively hinder SIRT1 activity, as no competition of this inhibitor with the $\mathrm{NAD}^{+}$molecule for the sirtuin 1 binding site was observed. However, nicotinic acid did not show the ability to inhibit SIRT1 [176]. In prostate neoplastic cells, the increased expression of SIRT1 compared to unchanged cells was diminished by the action of nicotinamide. Moreover, inhibition of the proliferation and growth of neoplastic cells was noted. The same effect was detected in cells in which the expression of this deacetylase was inhibited by the action of shRNA [222]. Studies carried out on cells from patients with chronic lymphocytic leukemia showed an augmented concentration of SIRT1 mRNA, compared to the B lymphocytes of healthy people. As a consequence of nicotinamide influence on these cells, the activity of SIRT1 is repressed and the apoptosis process is hyperactivated. Such a relationship was not detected during the suppression of p53 protein, which is a substrate for SIRT1. It seems that nicotinamide positively influences the induction of p53-dependent apoptosis by constraining the activity of SIRT1 [223].

\subsubsection{Salermide}

Salermide (N-\{3-[(2-hydroxy-naphthalen-1-ylmethylene)-amino]-phenyl\}-2-phenylpropionamide) is a reverse amide with a potent in vitro inhibitory effect on SIRT1 and SIRT2. It induces massive apoptosis in cancer but not in non-transformed cultured cells. The apoptotic effect of salermide is in part due to the reactivation of proapoptotic genes that are epigenetically repressed by SIRT1 exclusively in cancer cells [224].

\subsubsection{Selisistat}

Selisistat (6-chloro-2,3,4,9-tetrahydro-1H-carbazole-1-carboxamide) is a selective SIRT1 inhibitor. It is over 200 times more selective towards SIRT1 compared to SIRT2 and SIRT3. It has been shown to inhibit the deacetylation of several SIRT1 substrates both in vitro and in vivo. This compound shows cyto- and neuroprotective activity in Huntington's disease in both in vitro and in vivo models [225].

\subsubsection{Sirtinol}

Sirtinol is a synthetic chemical compound and specific sirtuin inhibitor. In vitro studies by Grozinger et al. [180] confirmed that the action of sirtinol resulted in a reduction of SIRT2 activity in yeast cells, while it had no effect on the activity of histone deacetylases. Cells treated with sirtinol for 24 and $48 \mathrm{~h}$ showed a reduced ability to proliferate. Moreover, the action of sirtinol leads to a drop in SIRT1 activity in relation to its substrate FoxO1 in the nucleus and the cytoplasm of these cells, which results in an increase in the degree of acetylation of this factor and the inhibition of its activity. The factor FoxO1 induces cell apoptosis, which leads to inhibition of the growth of neoplastic cells [222]. Exposing breast cancer cells to sirtinol causes a significant inhibition of their proliferation and stimulates them to initiate the process of cell death. This compound shows a greater inhibitory efficiency against SIRT1 than SIRT2. It interacts with SIRT1 by forming hydrogen bonds with Gln345 and His363 residues, while with SIRT2 it interacts by forming hydrogen bonds with Gln167. As an outcome of its inhibitory action, sirtinol contributes to an increase in the degree of acetylation of the lysine residue located at position 382 of the p53 protein, which results in its activation [177].

\subsubsection{SirReal2}

SirReal2 belongs to the family of aminothiazoles and is a potent and selective inhibitor of SIRT2 - $\mathrm{NAD}^{+}$-dependent lysine deacetylase that has been implicated in the pathogenesis of cancer, inflammation and neurodegeneration. SirReal2 inhibits SIRT2 only and has 
very little effect on the activities of SIRT3-5. The activities of SIRT1 and SIRT6 are slightly affected at higher SirReal2 concentrations, making SirReal2 one of the most selective sirtuin inhibitors [181].

\subsubsection{Suramin}

Suramin is an organic compound that is mainly used in the treatment of African sleep sickness caused by Trypanosoma and HIV infection [226]. It also shows antiproliferative and antiviral activity [7]. Studies by Schuetz et al. [227] showed that suramin has the ability to inhibit SIRT5 as a result of interaction with the substrate binding site for SIRT5 and with $\mathrm{NAD}^{+}$.

\subsubsection{Tenovin}

Tenovin is a bioactive small molecule that can exist in two isoforms: tenovin- 1 and tenovin-6. Tenovins have the ability to hinder the activity of SIRT1 and SIRT2 and to increase the degree of acetylation of the p53 protein [178]. Tenovin- 6 has also been shown to increase the intensity of cell apoptosis in acute promyelocytic leukemia, thereby inhibiting cell growth. In addition, the use of this inhibitor in treatment increased the differentiation of cells from the granulocyte lineage, as well as the surge in the degree of $\alpha$-tubulin acetylation - a substrate for SIRT2. This effect is related to the inhibition of SIRT2 activity, which is not observed in the case of SIRT1. On the other hand, in cells from the granulocyte lineage with improved SIRT2 expression, their differentiation is inhibited due to the action of tenovin-6 [228]. Studies by Nihal et al. [229] showed augmented expression of SIRT1 in Cutaneous T-cell Lymphoma. Inhibition of this deacetylase activity by shRNA resulted in an increase in the concentration of FoxO3 protein and in cell apoptosis. The same effect was obtained by the action of tenovin-1 on these cells. Additionally, this inhibitor increased the degree of p53 protein acetylation [229].

\section{Conclusions and Future Perspectives}

SIRTs are a family of multi-functional enzymes that can contribute to both strengthening and weakening the enzymatic activity of proteins and can also alter their expression. In our previous review we discussed the structure and biological functions of sirtuins, including the most important substrates for their catalytic activity and the role that sirtuins play in cellular processes [9]. The multidirectional catalytic activity of sirtuins makes them an interesting and important particles allowing for the understanding of many processes taking place in the cell. Understanding all the functions and mechanisms of sirtuins' action, as well as the interactions between SIRTs and modulators of their activity, is a great challenge for researchers. The acquired knowledge gives the opportunity to better understand the changes taking place in the cell, both in physiology and in pathology. It is particularly important to understand the influence of sirtuins on individual elements of the regulation of the process of DNA transcription and repair, regulation of cellular metabolism pathways and respiratory processes in cells, which could constitute an important point of reference for future diagnostic and therapeutic application. Despite the best understood role of SIRT1 and SIRT6 in modulating cellular processes, a growing area of research is also the investigation other classes of these enzymes. The role of SIRT5 seems to be of particular interest, due to its ability to catalyze demalonylation, deglutarylation and desuccinylation reactions, as well as its differentiated intracellular localization (cytoplasm, cell nucleus, mitochondria) [9].

There are many compounds known to regulate the activity of SIRTs, including ones of natural origin, which gives them great potential for use in the treatment of various diseases. However, despite the large number of investigations, the results of which contribute to the broadening of knowledge in this field, the development of an appropriate therapy based on SIRTs is still a challenging prospect. SIRTs regulate so many cellular processes that changing their activity can positively affect one process while at the same time negatively regulating another. The interesting aspect of its action is its role in oxidative stress development and 
its regulation by the Nrf2 factor, which is still poorly understood. Hence, it is extremely important to continue research along this path as well as examine the therapeutic use of SIRT while taking into account the role of activators and inhibitors that specifically influence their activity.

Author Contributions: Conceptualization, E.M.K. and A.P.; methodology, E.M.K., K.S., A.K.-K. and A.P.; writing - original draft preparation, E.M.K., K.S., A.K.-K. and A.P.; writing-review and editing, E.M.K. and A.P.; visualization, E.M.K., K.S., A.K.-K. and A.P.; funding acquisition, E.M.K. and A.P. All authors have read and agreed to the published version of the manuscript.

Funding: This research received no external funding.

Conflicts of Interest: Authors declare no conflict of interests.

\section{References}

1. Lipska, K.; Filip, A.A.; Gumieniczek, A. Advances in studies on histone deactylase inhibitors as anticancer drugs. Adv. Hyg. Exp. Med. 2018, 72, 1018-1031. [CrossRef]

2. Michan, S.; David Sinclair, D. Sirtuins in mammals: Insights into their biological function. Biochem. J. 2007, 404, 1-13. [CrossRef] [PubMed]

3. Teixeira, C.S.S.; Cerqueira, N.M.F.S.A.; Gomes, P.; Sousa, S.F. A Molecular Perspective on Sirtuin Activity. Int. J. Mol. Sci. 2020, 21, 8609. [CrossRef] [PubMed]

4. Morigi, M.; Perico, L.; Benigni, A. Sirtuins in Renal Health and Disease. J. Am. Soc. Nephrol. 2018, 29, 1799-1809. [CrossRef]

5. Sirtuins: Say "Yes SIR!" to Resveratrol. Available online: https://www.caymanchem.com/news/sirtuins-say-yes-sir-toresveratrol (accessed on 21 September 2020).

6. Yamamoto, H.; Schoonjans, K.; Auwerx, J. Sirtuin Functions in Health and Disease. Mol. Endocrinol. 2007, 21, 1745-1755. [CrossRef]

7. Villalba, J.M.; Francisco, J.A. Sirtuin activators and inhibitors. BioFactors 2012, 38, 349-359. [CrossRef]

8. Kane, A.E.; Sinclair, D.A. Sirtuins and NAD+ in the Development and Treatment of Metabolic and Cardiovascular Diseases. Circ. Res. 2018, 123, 868-885. [CrossRef]

9. Kratz, E.M.; Sołkiewicz, K.; Kaczmarek, A.; Piwowar, A. Sirtuins-enzymes with multidirectional catalytic activity. Adv. Hyg. Exp. Med. 2020, in press.

10. Kupis, W.; Pałyga, J.; Tomal, J.; Niewiadomska, E. The role of sirtuins in cellular homeostasis. J. Physiol. Biochem. 2016, 72, 371-380. [CrossRef]

11. Kahl, G. The Dictionary of Genomics, Transcriptomics and Proteomics; Wiley-VCH Verlag GmbH\&Co KGaA: Weinheim, Germany, 2015; p. 2156.

12. Siedlecka, K.; Bogusławski, W. Sirtuins-Longevity enzymes? Gerontol. Pol. 2005, 13, 147-152.

13. Schiedel, M.; Robaa, D.; Rumpf, T.; Sippl, W.; Jung, M. The current state of NAD+-dependent histone deacetylases (sirtuins) as novel therapeutic targets. Med. Res. Rev. 2017, 37, 1-54. [CrossRef] [PubMed]

14. Flick, F.; Lüscher, B. Regulation of Sirtuin Function by Posttranslational Modifications. Front. Pharmacol. 2012, 3, 29. [CrossRef] [PubMed]

15. Hikosaka, K.; Yaku, K.; Okabe, K.; Nakagawa, T. Implications of NAD metabolism in pathophysiology and therapeutics for neurodegenerative diseases. Nutr. Neurosci. 2019, 1-13. [CrossRef]

16. Caton, P.W.; Richardson, S.J.; Kieswich, J.; Bugliani, M.; Holland, M.L.; Marchetti, P.; Morgan, N.G.; Yagoob, M.M.; Holness, M.J.; Sugden, M.C. Sirtuin 3 regulates mouse pancreatic beta cell function and is suppresses in pancreatic islets isolated from human type 2 diabetic patients. Diabetologia 2013, 56, 1068-1077. [CrossRef] [PubMed]

17. Donmez, G.; Outeiro, T.F. SIRT1 and SIRT2: Emerging targets in neurodegeneration. EMBO Mol. Med. 2013, 5, 344-352. [CrossRef]

18. Huang, G.; Cheng, J.; Yu, F.; Liu, X.; Yuan, C.; Liu, C.; Chen, X.; Peng, Z. Clinical and therapeutic significance of sirtuin-4 expression in colorectal cancer. Oncol. Rep. 2016, 35, 2801-2810. [CrossRef]

19. Pacella-Ince, L.; Zander-Fox, D.L.; Lan, M. Mitochondrial SIRT3 and its target glutamate dehydrogenase are altered in follicular cells of women with reduced ovarian reserve or advanced maternal age. Hum. Reprod. 2014, 29, 1490-1499. [CrossRef]

20. Sebastian, C.; Satterstrom, F.K.; Haigis, M.C.; Mostoslavsky, R. From sirtuin biology to human diseases: An update. J. Biol. Chem. 2012, 287, 42444-42452. [CrossRef]

21. Palmeira, C.M.; Teodoro, J.S.; Amorim, J.A.; Steegborn, C.; Sinclair, D.A.; Rolo, A.P. Mitohormesis and metabolic health: The interplay between ROS, cAMP and sirtuins. Free Radic. Biol. Med. 2019, 141, 483-491. [CrossRef]

22. Houtkooper, R.H.; Pirinen, E.; Auwerx, J. Sirtuins as regulators of metabolism and healthspan. Nat. Rev. Mol. Cell Biol. 2012, 13, 225-238. [CrossRef]

23. Verdin, E. The Many Faces of Sirtuins: Coupling of NAD metabolism, sirtuins and lifespan. Nat. Med. 2014, 20, 25-27. [CrossRef] [PubMed]

24. Singh, C.K.; Chhabra, G.; Ndiaye, M.A.; Garcia-Peterson, L.M.; Mack, N.J.; Ahmad, N. The Role of Sirtuins in Antioxidant and Redox Signaling. Antioxid. Redox Signal. 2018, 28, 643-661. [CrossRef] [PubMed] 
25. Gomes, P.; Leal, H.; Mendes, A.F.; Reis, F.; Cavadas, C. Dichotomous Sirtuins: Implications for Drug Discovery in Neurodegenerative and Cardiometabolic Diseases. Trends Pharm. Sci. 2019, 40, 1021-1039. [CrossRef] [PubMed]

26. Pardo, P.S.; Mohamed, J.S.; Lopez, M.A.; Boriek, A.M. Induction of Sirt1 by mechanical stretch of skeletal muscle through the early response factor EGR1 triggers an antioxidative response. J. Biol. Chem. 2011, 286, 2559-2566. [CrossRef] [PubMed]

27. Tseng, A.H.H.; Shieh, S.S.; Wang, D.L. SIRT3 deacetylates FOXO3 to protect mitochondria against oxidative damage. Free Rad. Biol. Med. 2013, 63, 222-234. [CrossRef] [PubMed]

28. Ong, A.L.C.; Ramasamy, T.S. Role of Sirtuin1-p53 regulatory axis in aging, cancer and cellular reprogramming. Ageing Res. Rev. 2018, 43, 64-80. [CrossRef]

29. Brunet, A.; Sweeney, L.B.; Sturgill, J.F.; Chua, K.F.; Greer, P.L.; Lin, Y.; Tran, H.; Ross, S.E.; Mostoslavsky, R.; Cohen, H.Y.; et al. Stress-dependent regulation of FOXO transcription factors by the SIRT1 deacetylase. Science 2004, 303, 2011-2015. [CrossRef]

30. Hasegawa, K.; Wakino, S.; Yoshioka, K.; Tatematsu, S.; Hara, Y.; Minakuchi, H.; Washida, N.; Tokuyama, H.; Hayashi, K.; Itoh, H. Sirt1 protects against oxidative stress-induced renal tubular cell apoptosis by the bidirectional regulation of catalase expression. Biochem. Biophys. Res. Commun. 2008, 372, 51-56. [CrossRef]

31. de Kreutzenberg, S.V.; Ceolotto, G.; Papparella, I.; Bortoluzzi, A.; Semplicini, A.; Dalla Man, C.; Cobelli, C.; Fadini, G.P.; Avogaro, A. Downregulation of the longevity-associated protein sirtuin 1 in insulin resistance and metabolic syndrome: Potential biochemical mechanisms. Diabetes 2010, 59, 1006-1015. [CrossRef]

32. Caito, S.; Rajendrasozhan, S.; Cook, S.; Chung, S.; Yao, H.; Friedman, A.E.; Brookes, P.S.; Rahman, I. SIRT1 is a redoxsensitive deacetylase that is post-translationally modified by oxidants and carbonyl stress. FASEB J. 2010, 24, 3145-3159. [CrossRef]

33. Jung, S.B.; Kim, C.S.; Kim, Y.R.; Naqvi, A.; Yamamori, T.; Kumar, S.; Kumar, A.; Irani, K. Redox factor-1 activates endothelial SIRTUIN1 through reduction of conserved cysteine sulfhydryls in its deacetylase domain. PLoS ONE 2013, 8, e65415. [CrossRef] [PubMed]

34. Sasaki, T.; Maier, B.; Koclega, K.D. Phosphorylation regulates SIRT1 function. PLoS ONE 2008, 3, e4020. [CrossRef] [PubMed]

35. Alexandrou, A.T.; Li, J.J. Cell cycle regulators guide mitochondrial activity in radiation-induced adaptive response. Antioxid. Redox Signal. 2014, 20, 1463-1480. [CrossRef] [PubMed]

36. Kang, H.; Jung, J.W.; Kim, M.K.; Chung, J.H. CK2 is the regulator of SIRT1 substrate-binding affinity, deacetylase activity and cellular response to DNA-damage. PLoS ONE 2009, 4, e6611. [CrossRef]

37. Nin, V.; Escande, C.; Chini, C.C.; Giri, S.; Camacho-Pereira, J.; Matalonga, J.; Lou, Z.; Chini, E.N. Role of deleted in breast cancer 1 (DBC1) protein in SIRT1 deacetylase activation induced by protein kinase A and AMP-activated protein kinase. J. Biol. Chem. 2012, 287, 23489-23501. [CrossRef]

38. Lau, A.W.; Liu, P.; Inuzuka, H.; Gao, D. SIRT1 phosphorylation by AMP-activated protein kinase regulates p53 acetylation. Am. J. Cancer Res. 2014, 4, 245-255.

39. North, B.J.; Verdin, E.L. Mitotic regulation of SIRT2 by cyclin-dependent kinase 1-dependent phosphorylation. J. Biol. Chem. 2007, 282, 19546-19555. [CrossRef]

40. Dephoure, N.; Zhou, C.; Villen, J.; Beausoleil, S.A.; Bakalarski, C.E.; Elledge, S.J.; Gygi, S.P. A quantitative atlas of mitotic phosphorylation. Proc. Natl. Acad. Sci. USA 2008, 105, 10762-10767. [CrossRef]

41. Thirumurthi, U.; Shen, J.; Xia, W.; LaBaff, A.M.; Wei, Y.; Li, C.W.; Chang, W.C.; Chen, C.H.; Lin, H.K.; Yu, D.; et al. MDM2mediated degradation of SIRT6 phosphorylated by AKT1 promotes tumorigenesis and trastuzumab resistance in breast cancer. Sci. Signal. 2014, 7, ra71. [CrossRef]

42. Yang, S.R.; Wright, J.; Bauter, M.; Seweryniak, K.; Kode, A.; Rahman, I. Sirtuin regulates cigarette smoke-induced proinflammatory mediator release via RelA/p65 NF- $\mathrm{BB}$ in macrophages in vitro and in rat lungs in vivo: Implications for chronic inflammation and aging. Am. J. Physiol. Lung Cell. Mol. Physiol. 2007, 292, L567-L576. [CrossRef]

43. Kornberg, M.D.; Sen, N.; Hara, M.R.; Juluri, K.R.; Nguyen, J.V.; Snowman, A.M.; Law, L.; Hester, L.D.; Snyder, S.H. GAPDH mediates nitrosylation of nuclear proteins. Nat. Cell Biol. 2010, 12, 1094-1100. [CrossRef] [PubMed]

44. Hu, A.; Huang, J.J.; Li, R.L.; Lu, Z.Y.; Duan, J.I.; Xu, W.H.; Chen, X.P.; Fan, J.P. Curcumin as therapeutics for the treatment of head and neck squamous cell carcinoma by activating SIRT1. Sci. Rep. 2015, 5, 13429. [CrossRef] [PubMed]

45. Kim, J.E.; Chen, J.; Lou, Z. DBC1 is a negative regulator of SIRT1. Nature 2008, 451, 583-586. [CrossRef] [PubMed]

46. Kim, E.J.; Kho, J.H.; Kang, M.R.; Um, S.J. Active regulator of SIRT1 cooperates with SIRT1 and facilitates suppression of p53 activity. Mol. Cell 2007, 28, 277-290. [CrossRef] [PubMed]

47. Knight, J.R.P.; Allison, S.J.; Milner, J. Active regulator of SIRT1 is required for cancer cell survival but not for SIRT1 activity. Open Biol. 2013, 3, 130130. [CrossRef]

48. Chini, E.N. CD38 as a regulator of cellular NAD: A novel potential pharmacological target for metabolic conditions. Curr. Pharm. Des. 2009, 15, 57-63. [CrossRef]

49. Escande, C.; Nin, V.; Price, N.L.; Capellini, V.; Gomes, A.P.; Barbosa, M.T.; O’Neil, L.; White, T.A.; Sinclair, D.A.; Chini, E.N. Flavonoid apigenin is an inhibitor of the NAD+ase CD38: Implications for cellular NAD+ metabolism, protein acetylation, and treatment of metabolic syndrome. Diabetes 2013, 62, 1084-1093. [CrossRef]

50. Bai, P.; Cantó, C.; Oudart, H.; Brunyánszki, A.; Cen, Y.; Yamamoto, H.; Huber, A.; Kiss, B.; Houtkooper, R.H.; Schoonjans, K.; et al. PARP-1 Inhibition Increases Mitochondrial Metabolism through SIRT1 Activation. Cell Metab. 2011, 13, 461-468. [CrossRef]

51. Szántó, M.; Bai, P. The role of ADP-ribose metabolism in metabolic regulation, adipose tissue differentiation, and metabolism. Genes Dev. 2020, 34, 321-340. [CrossRef] 
52. Iwahara, T.; Bonasio, R.; Narendra, V.; Reinberg, D. SIRT3 functions in the nucleus in the control of stressrelated gene expression. Mol. Cell. Biol. 2012, 32, 5022-5034. [CrossRef]

53. Verdin, E.; Hirschey, M.D.; Finley, L.W.; Haigis, M.C. Sirtuin regulation of mitochondria: Energy production, apoptosis, and signaling. Trends Biochem. Sci. 2010, 35, 669-675. [CrossRef] [PubMed]

54. Haigis, M.C.; Deng, C.X.; Finley, L.W.; Kim, H.S.; Gius, D. SIRT3 is a mitochondrial tumor suppressor: A scientific tale that connects aberrant cellular ROS, the Warburg effect, and carcinogenesis. Cancer Res. 2012, 72, 2468-2472. [CrossRef] [PubMed]

55. Schon, E.A. Mitochondrial genetics and disease. Trends Biochem. Sci. 2000, 25, 555-560. [CrossRef]

56. Cheng, Y.; Ren, X.; Gowda, A.S.; Shan, Y.; Zhang, L.; Yuan, Y.S.; Patel, R.; Wu, H.; Huber-Keener, K.; Yang, J.W.; et al. Interaction of Sirt3 with OGG1 contributes to repair of mitochondrial DNA and protects from apoptotic cell death under oxidative stress. Cell Death Dis. 2013, 4, e731. [CrossRef] [PubMed]

57. Anderson, K.A.; Huynh, F.K.; Fisher-Wellman, K.; Stuart, J.D.; Peterson, B.S.; Douros, J.D.; Wagner, G.R.; Thompson, J.W.; Madsen, A.S.; Green, M.F.; et al. SIRT4 is a lysine deacylase that controls leucine metabolism and insulin secretion. Cell. Metab. 2017, 25, 838-855. [CrossRef]

58. Grabowska, W.; Sikora, E.; Bielak-Zmijewska, A. Sirtuins, a promising target in slowing down the ageing process. Biogerontology 2017, 18, 447-476. [CrossRef]

59. Shinmura, K. Effects of caloric restriction on cardiac oxidative stress and mitochondrial bioenergetics: Potential role of cardiac sirtuins. Oxid. Med. Cell. Longev. 2013, 2013, 528935. [CrossRef]

60. Watroba, M.; Szukiewicz, D. The role of sirtuins in aging and age-related diseases. Adv. Med. Sci. 2016, 61, 52-62. [CrossRef]

61. Du, J.; Zhou, Y.; Su, X.; Yu, J.J.; Khan, S.; Jiang, H.; Kim, J.; Woo, J.; Kim, J.H.; Choi, B.H.; et al. Sirt5 is a NAD dependent protein lysine demalonylase and desuccinylase. Science 2011, 334, 806-809. [CrossRef]

62. Liu, B.; Che, W.; Zheng, C.; Liu, W.; Wen, J.; Fu, H.; Tang, K.; Zhang, J.; Xu, Y. SIRT5: A safeguard against oxidative stress-induced apoptosis in cardiomyocytes. Cell. Physiol. Biochem. 2013, 32, 1050-1059. [CrossRef]

63. Nakagawa, T.; Lomb, D.J.; Haigis, M.C.; Guarente, L. SIRT5 Deacetylates carbamoyl phosphate synthetase 1 and regulates the urea cycle. Cell 2009, 137, 560-570. [CrossRef] [PubMed]

64. Yang, L.; Ma, X.; He, Y.; Yuan, C.; Chen, Q.; Li, G.; Chen, X. Sirtuin 5: A review of structure, known inhibitors and clues for developing new inhibitors. Sci. China Life Sci. 2017, 60, 249-256. [CrossRef] [PubMed]

65. Bobermin, L.D.; Wartchow, K.M.; Flores, M.P.; Leite, M.C.; Quincozes-Santos, A.; Goncalves, C.A. Ammonia-induced oxidative damage in neurons is prevented by resveratrol and lipoic acid with participation of heme oxygenase 1. Neurotoxicology 2015, 49, 28-35. [CrossRef] [PubMed]

66. Schlicker, C.; Gertz, M.; Papatheodorou, P.; Kachholz, B.; Becker, C.F.; Steegborn, C. Substrates and regulation mechanisms for the human mitochondrial sirtuins Sirt3 and Sirt5. J. Mol. Biol. 2008, 382, 790-801. [CrossRef] [PubMed]

67. Liang, F.; Wang, X.; Ow, S.H.; Chen, W.; Ong, W.C. Sirtuin 5 is Anti-apoptotic and anti-oxidative in cultured SH-EP neuroblastoma cells. Neurotox. Res. 2017, 31, 63-76. [CrossRef] [PubMed]

68. Liou, G.G.; Tanny, J.C.; Kruger, R.G.; Walz, T.; Moazed, D. Assembly of the SIR complex and its regulation by O-acetyl-ADP-ribose, a product of NAD-dependent histone deacetylation. Cell 2005, 121, 515-527. [CrossRef] [PubMed]

69. Cuadrado, A. Structural and functional characterization of Nrf2 degradation by glycogen synthase kinase $3 / \beta$-TrCP. Free Radic. Biol. Med. 2015, 88, 147-157. [CrossRef] [PubMed]

70. Chen, Q.M.; Maltagliati, A.J. Nrf2 at the heart of oxidative stress and cardiac protection. Physiol. Genom. 2018, 50, 77-97. [CrossRef]

71. Kawai, Y.; Garduño, L.; Theodore, M.; Yang, J.; Arinze, I.J. Acetylation-deacetylation of the transcription factor Nrf2 (nuclear factor erythroid 2-related factor 2) regulates its transcriptional activity and nucleocytoplasmic localization. J. Biol. Chem. 2011, 286, 7629-7640. [CrossRef]

72. Huang, K.; Huang, J.; Xie, X.; Wang, S.; Chen, C.; Shen, X.; Liu, P.; Huang, H. Sirt1 resists advanced glycation end productsinduced expressions of fibronectin and TGF- $\beta 1$ by activating the Nrf2/ARE pathway in glomerular mesangial cells. Free Radic. Biol. Med. 2013, 65, 528-540. [CrossRef]

73. Yang, Y.; Li, W.; Liu, Y.; Sun, Y.; Li, Y.; Yao, Q.; Li, J.; Zhang, Q.; Gao, Y.; Gao, L.; et al. Alpha-lipoic acid improves high-fat diet-induced hepatic steatosis by modulating the transcription factors SREBP-1, FoxO1 and Nrf2 via the SIRT1/LKB1/AMPK pathway. J. Nutr. Biochem. 2014, 25, 1207-1217. [CrossRef] [PubMed]

74. Huang, G.; Cui, F.; Yu, F.; Lu, H.; Zhang, M.; Tang, H.; Peng, Z. Sirtuin-4 (SIRT4) is downregulated and associated with some clinicopathological features in gastric adenocarcinoma. Biomed. Pharmacother. 2015, 72, 135-139. [CrossRef] [PubMed]

75. Ding, Y.W.; Zhao, G.J.; Li, X.L.; Hong, G.L.; Li, M.F.; Qiu, Q.M.; Wu, B.; Lu, Z.Q. SIRT1 exerts protective effects against paraquatinduced injury in mouse type II alveolar epithelial cells by deacetylating NRF2 in vitro. Int. J. Mol. Med. 2016, 37, 1049-1058. [CrossRef] [PubMed]

76. Mercado, N.; Thimmulappa, R.; Thomas, C.M.R.; Fenwick, P.S.; Chana, K.K.; Donnelly, L.E.; Biswal, S.; Ito, K.; Barnes, P.J. Decreased histone deacetylase 2 impairs Nrf2 activation by oxidative stress. Biochem. Biophys. Res. Commun. 2011, 406, 292-298. [CrossRef] [PubMed]

77. Yang, X.; Park, S.H.; Chang, H.C.; Shapiro, J.S.; Vassilopoulos, A.; Sawicki, K.T.; Chen, C.; Shang, M.; Burridge, P.W.; Epting, C.; et al. Sirtuin 2 regulates cellular iron homeostasis via deacetylation of transcription factor NRF2. J. Clin. Investig. 2017, 127, 1505-1516. [CrossRef] 
78. Cao, W.; Hong, Y.; Chen, H.; Wu, F.; Wei, X.; Ying, W. SIRT2 mediates NADH-induced increases in Nrf2, GCL, and glutathione by modulating Akt phosphorylation in PC12 cells. Febs Lett. 2016, 590, 2241-2255. [CrossRef]

79. Zhang, J.; Hong, Y.; Cao, W.; Yin, S.; Shi, H.; Ying, W. SIRT2, ERK and Nrf2 mediate NAD+ treatment-induced increase in the antioxidant capacity of PC12 cells under basal conditions. Front. Mol. Neurosci. 2019, 12, 108. [CrossRef]

80. McDougald, D.S.; Dine, K.E.; Zezulin, A.U.; Bennett, J.; Shindler, K.S. SIRT1 and NRF2 gene transfer mediate distinct neuroprotective effects upon retinal ganglion cell survival and function in experimental optic neuritis. Investig. Ophthalmol. Vis. Sci. 2018, 59, 1212-1220. [CrossRef]

81. Huang, K.; Gao, X.; Wei, W. The crosstalk between Sirt1 and Keap1/Nrf2/ARE anti-oxidative pathway forms a positive feedback loop to inhibit FN and TGF- $\beta 1$ expressions in rat glomerular mesangial cells. Exp. Cell Res. 2017, 361, 63-72. [CrossRef]

82. Salminen, A.; Ojala, J.; Huuskonen, J.; Kauppinen, A.; Suuronen, T.; Kaarniranta, K. Interaction of aging-associated signaling cascades: Inhibition of NF-kappaB signaling by longevity factors FoxOs and SIRT1. Cell. Mol. Life Sci. 2008, 65, 1049-1058. [CrossRef]

83. Chen, J.; Zhou, Y.; Mueller-Steiner, S.; Chen, L.-F.; Kwon, H.; Yi, S.; Mucke, L.; Gan, L. SIRT1 protects against microglia-dependent amyloid-beta toxicity through inhibiting NF-kappaB signaling. J. Biol. Chem. 2005, 280, 40364-40374. [CrossRef] [PubMed]

84. Kawahara, T.L.A.; Michishita, E.; Adler, A.S.; Damian, M.; Berber, E.; Lin, M.; McCord, R.A.; Ongaigui, K.C.L.; Boxer, L.D.; Chang, H.Y.; et al. SIRT6 links histone H3 lysine 9 deacetylation to control of NF- $\mathrm{kB}$ dependent gene expression and organismal lifespan. Cell 2009, 136, 62-74. [CrossRef] [PubMed]

85. Yeung, F.; Hoberg, J.E.; Ramsey, C.S.; Keller, M.D.; Jones, D.R.; Frye, R.A.; Mayo, M.W. Modulation of NF-kappaB-dependent transcription and cell survival by the SIRT1 deacetylase. EMBO J. 2004, 23, 2369-2380. [CrossRef] [PubMed]

86. Ghosh, H.S.; Spencer, J.V.; Ng, B.; McBurney, M.W.; Robbins, P.D. Sirt1 interacts with transducin-like enhancer of split-1 to inhibit nuclear factor kappaB-mediated transcription. Biochem. J. 2007, 408, 105-111. [CrossRef] [PubMed]

87. Sasso, G.L.; Menzies, K.J.; Mottis, A.; Piersigilli, A.; Perino, A.; Yamamoto, H.; Schoonjans, K.; Auwerx, J. SIRT2 deficiency modulates macrophage polarization and susceptibility to experimental colitis. PLoS ONE 2014, 9, e103573. [CrossRef]

88. Song, Y.; Shi, J.; Wu, Y.; Han, C.; Zou, J.; Shi, Y.; Liu, Z. Metformin ameliorates insulin resistance in L6 rat skeletal muscle cells through upregulation of SIRT3. Chin. Med. J. 2014, 127, 1523-1529. [PubMed]

89. Chen, Y.; Wang, H.; Luo, G.; Dai, X. SIRT4 inhibits cigarette smoke extracts-induced mononuclear cell adhesion to human pulmonary microvascular endothelial cells via regulating NF-kB activity. Toxicol. Lett. 2014, 226, 320-327. [CrossRef]

90. Tao, Y.; Huang, C.; Huang, Y.; Hong, L.; Wang, H.; Zhou, Z.; Qiu, Y. SIRT4 Suppresses Inflammatory Responses in Human Umbilical Vein Endothelial Cells. Cardiovasc. Toxicol. 2015, 15, 217-223. [CrossRef]

91. Gustin, J.A.; Korgaonkar, C.K.; Pincheira, R.; Li, Q.; Donner, D.B. Akt regulates basal and induced processing of NF-kappaB2 (p100) to p52. J. Biol. Chem. 2006, 281, 16473-16481. [CrossRef]

92. Bouras, T.; Fu, M.; Sauve, A.A.; Wang, F.; Quong, A.A.; Perkins, N.D.; Hay, R.T.; Gu, W.; Pestell, R.G. SIRT1 deacetylation and repression of p300 involves lysine residues 1020/1024 within the cell cycle regulatory domain 1. J. Biol. Chem. 2005, 280, 10264-10276. [CrossRef]

93. Black, J.C.; Mosley, A.; Kitada, T.; Washburn, M.; Carey, M. The SIRT2 deacetylase regulates autoacetylation of p300. Mol. Cell. 2008, 32, 449-455. [CrossRef] [PubMed]

94. Han, Y.; Jin, Y.H.; Kim, Y.J.; Kang, B.Y.; Choi, H.J.; Kim, D.W.; Yeo, C.Y.; Lee, K.Y. Acetylation of Sirt2 by p300 attenuates its deacetylase activity. Biochem. Biophys. Res. Commun. 2008, 375, 576-580. [CrossRef] [PubMed]

95. Buck, E.; Bayer, H.; Lindenberg, K.S.; Hanselmann, J.; Pasquarelli, N.; Ludolph, A.C.; Weydt, P.; Witting, A. Comparison of sirtuin 3 Levels in ALS and Huntington's disease-differential effects in human tissue samples vs. Transgenic Mouse Models. Front. Mol. Neurosci. 2017, 10, 156. [CrossRef] [PubMed]

96. Chopra, V.; Quinti, L.; Kim, J.; Vollor, L.; Narayanan, K.L.; Edgerly, C.; Cipicchio, P.M.; Lauver, M.A.; Choi, S.H.; Silverman, R.B.; et al. The sirtuin 2 inhibitor AK-7 is neuroprotective in Huntington's disease mouse models. Cell. Rep. 2012, 2, $1492-1497$. [CrossRef] [PubMed]

97. Julien, C.; Tremblay, C.; Emond, V.; Lebbadi, M.; Salem, N., Jr.; Bennett, D.A.; Calon, F. Sirtuin 1 reduction parallels the accumulation of tau in Alzheimer disease. J. Neurpathol. Exp. Neurol. 2009, 68, 48-58. [CrossRef]

98. Min, L.; Ji, Y.; Bakiri, L.; Qiu, Z.; Cen, J.; Chen, X.; Chen, L.; Scheuch, H.; Zheng, H.; Qin, L.; et al. Liver cancer initiation is controlled by AP-1 through SIRT6-dependent inhibition of survivin. Nat. Cell Biol. 2012, 14, 1203-1211. [CrossRef]

99. Min, S.W.; Sohn, P.D.; Li, Y.; Devidze, N.; Johnson, J.R.; Krogan, N.J.; Masliah, E.; Mok, S.A.; Gestwicki, J.E.; Gan, L. SIRT1 Deacetylates Tau and Reduces Pathogenic Tau Spread in a Mouse Model of Tauopathy. J. Neurosci. 2018, 38, 3680-3688. [CrossRef]

100. Shindler, K.S.; Ventura, E.; Dutt, M.; Elliott, P.; Fitzgerald, D.C.; Rostami, A. Oral resveratrol reduces neuronal damage in a model of multiple sclerosis. J. Neuroophthalmol. 2010, 30, 328-339. [CrossRef]

101. Wang, R.; Li, J.J.; Diao, S.; Kwak, Y.D.; Liu, L.; Zhi, L.; Büeler, H.; Bhat, N.R.; Williams, R.W.; Park, E.A.; et al. Metabolic stress modulates Alzheimer's beta-secretase gene transcription via SIRT1-PPARgamma-PGC-1 in neurons. Cell Metab. 2013, 17, 685-694. [CrossRef]

102. Weir, H.J.; Murray, T.K.; Kehoe, P.G.; Love, S.; Verdin, E.M.; O’Neill, M.J.; Lane, J.D.; Balthasar, N. CNS SIRT3 expression is altered by reactive oxygen species and in Alzheimer's disease. PLoS ONE 2012, 7, e48225. [CrossRef]

103. Giblin, W.; Skinner, M.E.; Lombard, D.B. Sirtuins: Guardians of mammalian healthspan. Trends Genet. 2014, 30, 271-286. [CrossRef] [PubMed] 
104. Bradbury, C.A.; Khanim, F.L.; Hayden, R.; Bunce, C.M.; White, D.A.; Drayson, M.T.; Craddock, C.; Turner, B.M. Histone deacetylases in acute myeloid leukaemia show a distinctive pattern of expression that changes selectively in response to deacetylase inhibitors. Leukemia 2005, 19, 1751-1759. [CrossRef]

105. Bhalla, S.; Gordon, L.I. Functional characterization of NAD dependent de-acetylases SIRT1 and SIRT2 in B-Cell Chronic Lymphocytic Leukemia (CLL). Cancer Biol. 2016, 17, 300-309. [CrossRef] [PubMed]

106. Cha, E.J.; Noh, S.J.; Kwon, K.S.; Kim, C.Y.; Park, B.H.; Park, H.S.; Lee, H.; Chung, M.J.; Kang, M.J.; Lee, D.G.; et al. Expression of DBC1 and SIRT1 is associated with poor prognosis of gastric carcinoma. Clin. Cancer Res. 2009, 15, 4453-4459. [CrossRef] [PubMed]

107. Stunkel, W.; Peh, B.K.; Tan, Y.C.; Nayagam, V.M.; Wang, X.; Salto-Tellez, M.; Ni, B.; Entzeroth, M.; Wood, J. Function of the SIRT1 protein deacetylase in cancer. Biotechnol. J. 2007, 2, 1360-1368. [CrossRef] [PubMed]

108. Huffman, D.M.; Grizzle, W.E.; Bamman, M.M.; Kim, J.; Eltoum, I.A.; Elgavish, A.; Nagy, T.R. SIRT1 is significantly elevated in mouse and human prostate cancer. Cancer Res. 2007, 67, 6612-6618. [CrossRef] [PubMed]

109. Derr, R.S.; van Hoesel, A.Q.; Benard, A.; Goossens-Beumer, I.J.; Sajet, A.; Dekker-Ensink, N.G.; de Kruijf, E.M.; Bastiaannet, E High nuclear expression levels of histone-modifying enzymes LSD1, HDAC2 and SIRT1 in tumor cells correlate with decreased survival and increased relapse in breast cancer patients. BMC Cancer 2014, 14, 604. [CrossRef] [PubMed]

110. Lee, H.; Kim, K.R.; Noh, S.J.; Park, H.S.; Kwon, K.S.; Park, B.H.; Jung, S.H.; Youn, H.J.; Lee, B.K.; Chung, M.J.; et al. Expression of DBC1 and SIRT1 is associated with poor prognosis for breast carcinoma. Hum. Pathol. 2011, 42, 204-213. [CrossRef]

111. Hida, Y.; Kubo, Y.; Murao, K.; Arase, S. Strong expression of a longevity-related protein, SIRT1, in Bowen's disease. Arch. Derm. Res. 2007, 299, 103-106. [CrossRef]

112. Noh, S.J.; Baek, H.A.; Park, H.S.; Jang, K.Y.; Moon, W.S.; Kang, M.J.; Lee, D.G.; Kim, M.H.; Lee, J.H.; Chung, M.J. Expression of SIRT1 and cortactin is associated with progression of non-small cell lung cancer. Pathol. Res. Pr. 2013, 209, 365-370. [CrossRef]

113. Chang, C.J.; Hsu, C.C.; Yung, M.C.; Chen, K.Y.; Tzao, C.; Wu, W.F.; Chou, H.Y.; Lee, Y.Y.; Lu, K.H.; Chiou, S.H.; et al. Enhanced radiosensitivity and radiation-induced apoptosis in glioma CD133-positive cells by knockdown of SirT1 expression. Biochem. Biophys. Res. Commun. 2009, 380, 236-242. [CrossRef] [PubMed]

114. Jang, S.H.; Min, K.W.; Paik, S.S.; Jang, K.S. Loss of SIRT1 histone deacetylase expression associates with tumour progression in colorectal adenocarcinoma. J. Clin. Pathol. 2012, 65, 735-773. [CrossRef] [PubMed]

115. Donmez, G. The Effects of SIRT1 on Alzheimer's Disease Models. Int. J. Alzheimers Dis. 2012, 2012, 509529. [CrossRef] [PubMed]

116. Lalla, R.; Donmez, G. The role of sirtuins in Alzheimer's disease. Front. Aging Neurosci. 2013, 5, 16. [CrossRef] [PubMed]

117. Dan, L.; Klimenkova, O.; Klimiankou, M.; Klusman, J.H.; van den Heuvel-Eibrink, M.M.; Reinhardt, D.; Welte, K.; Skokowa, J. The role of sirtuin 2 activation by nicotinamide phosphoribosyltransferase in the aberrant proliferation and survival of myeloid leukemia cells. Haematologica 2012, 97, 551-559. [CrossRef] [PubMed]

118. Hou, H.; Chen, W.; Zhao, L.; Zuo, Q.; Zhang, G.; Zhang, X.; Wang, H.; Gong, H.; Li, X.; Wang, M.; et al. Cortactin is associated with tumour progression and poor prognosis in prostate cancer and SIRT2 other than HADC6 may work as facilitator in situ. J. Clin. Pathol. 2012, 65, 1088-1096. [CrossRef] [PubMed]

119. Kim, H.S.; Vassilopoulos, A.; Wang, R.H.; Lahusen, T.; Xiao, Z.; Xu, X.; Li, C.; Veenstra, T.D.; Li, B.; Yu, H.; et al. SIRT2 maintains genome integrity and suppresses tumorigenesis through regulating APC/C activity. Cancer Cell 2011, 20, 487-499. [CrossRef]

120. Ming, M.; Han, W.; Zhao, B.; Sundaresan, N.R.; Deng, C.X.; Gupta, M.P.; He, Y.Y. SIRT6 promotes COX-2 expression and acts as an oncogene in skin cancer. Cancer Res. 2014, 74, 5925-5933. [CrossRef]

121. Ming, M.; Qiang, L.; Zhao, B.; He, Y.Y. Mammalian SIRT2 inhibits keratin 19 expression and is a tumor suppressor in skin. Exp. Derm. 2014, 23, 207-209. [CrossRef]

122. Hiratsuka, M.; Inoue, T.; Toda, T.; Kimura, N.; Shirayoshi, Y.; Kamitani, H.; Watanabe, T.; Ohama, E.; Tahimic, C.G.T.; Kurimasa, A.; et al. Proteomics-based identification of differentially expressed genes in human gliomas: Down-regulation of SIRT2 gene. Biochem. Biophys. Res. Commun. 2003, 309, 558-566. [CrossRef]

123. Torrens-Mas, M.; Hernández-López, R.; Pons, D.G.; Roca, P.; Oliver, J.; Sastre-Serra, J. Sirtuin 3 silencing impairs mitochondrial biogenesis and metabolism in colon cancer cells. Am. J. Physiol. Cell. Physiol. 2019, 317, 398-404. [CrossRef] [PubMed]

124. Cui, Y.; Qin, L.; Wu, J.; Qu, X.; Hou, C.; Sun, W.; Li, S.; Vaughan, A.T.; Li, J.J.; Liu, J. SIRT3 Enhances Glycolysis and Proliferation in SIRT3-Expressing Gastric Cancer Cells. PLoS ONE 2015, 10, e0129834. [CrossRef] [PubMed]

125. Finley, L.W.; Carracedo, A.; Lee, J.; Souza, A.; Egia, A.; Zhang, J.; Teruya-Feldstein, J.; Moreira, P.I.; Cardoso, S.M.; Clish, C.B.; et al. SIRT3 opposes reprogramming of cancer cell metabolism through HIF1 $\alpha$ destabilization. Cancer Cell 2011, 19, 416-428. [CrossRef] [PubMed]

126. Zhang, C.Z.; Liu, L.; Cai, M.; Pan, Y.; Fu, J.; Cao, Y.; Yun, J. Low SIRT3 expression correlates with poor differentiation and unfavorable prognosis in primary hepatocellular carcinoma. PLoS ONE 2012, 7, e51703. [CrossRef] [PubMed]

127. Zhang, Y.Y.; Zhou, L.M. Sirt3 inhibits hepatocellular carcinoma cell growth through reducing Mdm2-mediated p53 degradation. Biochem. Biophys. Res. Commun. 2012, 423, 26-31. [CrossRef]

128. McGlynn, L.M.; McCluney, S.; Jamieson, N.B.; Thomson, J.; MacDonald, A.I.; Oien, K.; Dickson, E.J.; Carter, C.R.; McKay, C.J.; Shiels, P.G. SIRT3 \& SIRT7: Potential Novel Biomarkers for Determining Outcome in Pancreatic Cancer Patients. PLoS ONE 2015, 10, e0131344. [CrossRef]

129. Yu, W.; Denu, R.A.; Krautkramer, K.A.; Grindle, K.M.; Yang, D.T.; Asimakopoulos, F.; Hematti, P.; Denu, J.M. Loss of SIRT3 Provides Growth Advantage for B Cell Malignancies. J. Biol. Chem. 2016, 291, 3268-3279. [CrossRef] 
130. Lai, X.; Yu, Z.; Chen, X.; Huang, G. SIRT4 is upregulated in Chinese patients with esophageal cancer. Int. J. Clin. Exp. Pathol. 2016, 9, 10543-10549.

131. Shi, Q.; Liu, T.; Zhang, X.; Geng, J.; He, X.; Nu, M.; Pang, D. Decreased sirtuin 4 expression is associated with poor prognosis in patients with invasive breast cancer. Oncol. Lett. 2016, 12, 2606-2612. [CrossRef]

132. Chen, Z.; Lin, J.; Feng, S.; Chen, X.; Huang, H.; Wang, C.; Yu, Y.; He, Y.; Han, S.; Zheng, L.; et al. SIRT4 inhibits the proliferation, migration, and invasion abilities of thyroid cancer cells by inhibiting glutamine metabolism. Onco Targets 2019, 12, $2397-2408$. [CrossRef]

133. Luo, Y.-X.; Tang, X.; An, X.-Z.; Xie, X.-M.; Chen, X.-F.; Zhao, X.; Hao, D.-L.; Chen, H.-Z.; Liu, D.-P. Sirt4 accelerates Ang II-induced pathological cardiac hypertrophy by inhibiting manganese superoxide dismutase activity. Eur. Heart J. 2017, 38, 1389-1398. [CrossRef] [PubMed]

134. Sun, H.; Huang, D.; Liu, G.; Jian, F.; Zhu, J.; Zhang, L. SIRT4 acts as a tumor suppressor in gastric cancer by inhibiting cell proliferation, migration, and invasion. Onco Targets 2018, 11, 3959-3968. [CrossRef] [PubMed]

135. Huang, G.; Lai, X.; Chen, Z.; Yu, Z.; Zhou, D.; Wang, P.; Zhou, H.; Zhu, G. Sirtuin-4 (SIRT4) is downregulated in hepatocellular carcinoma and associated with clinical stage. Int. J. Clin. Exp. Pathol. 2016, 9, 6511-6517.

136. Miyo, M.; Yamamoto, H.; Konno, M.; Colvin, H.; Nishida, N.; Koseki, J.; Kawamoto, K.; Ogawa, H.; Hamabe, A.; Uemura, M.; et al. Tumour-suppressive function of SIRT4 in human colorectal cancer. Br. J. Cancer 2015, 113, 492-499. [CrossRef]

137. Bartosch, C.; Monteiro-Reis, S.; Almeida-Rios, D.; Vieira, R.; Castro, A.; Moutinho, M.; Rodrigues, M.; Graça, I.; Lopes, J.M.; Jerónimo, C. Assessing sirtuin expression in endometrial carcinoma and non-neoplastic endometrium. Oncotarget 2016, 7, 1144-1154. [CrossRef]

138. Nakahara, Y.; Yamasaki, M.; Sawada, G.; Miyazaki, Y.; Makino, T.; Takahashi, T.; Kurokawa, Y.; Nakajima, K.; Takiguchi, S.; Mimori, K.; et al. Downregulation of SIRT4 expression is associated with poor prognosis in esophageal squamous cell carcinoma. Oncology 2016, 90, 347-355. [CrossRef]

139. Lu, W.; Zuo, Y.; Feng, Y.; Zhang, M. SIRT5 facilitates cancer cell growth and drug resistance in non-small cell lung cancer. Tumour Biol. 2014, 35, 10699-10705. [CrossRef]

140. Shi, L.; Yan, H.; An, S.; Shen, M.; Jia, W.; Zhang, R.; Zhao, L.; Huang, G.; Liu, J. SIRT5-mediated deacetylation of LDHB promotes autophagy and tumorigenesis in colorectal cancer. Mol. Oncol. 2019, 13, 358-375. [CrossRef]

141. Wang, Y.Q.; Wang, H.L.; Xu, J.; Tan, J.; Fu, L.N.; Wang, J.L.; Zou, T.H.; Sun, D.F.; Gao, Q.Y.; Chen, Y.X.; et al. Sirtuin 5 contributes to colorectal carcinogenesis by enhancing glutaminolysis in a deglutarylation-dependent manner. Nat. Commun. 2018, 9, 545. [CrossRef]

142. Zhang, R.; Wang, C.; Tian, Y.; Yao, Y.; Mao, J.; Wanh, H.; Li, Z.; Xu, Y.; Ye, M.; Wang, L. SIRT5 Promotes Hepatocellular Carcinoma Progression by Regulating Mitochondrial Apoptosis. J. Cancer 2019, 10, 3871-3882. [CrossRef]

143. Sun, X.; Wang, S.; Gai, J.; Guan, J.; Li, J.; Li, Y.; Zhao, J.; Zhao, C.; Fu, L.; Li, Q. SIRT5 Promotes Cisplatin Resistance in Ovarian Cancer by Suppressing DNA Damage in a ROS-Dependent Manner via Regulation of the Nrf2/HO-1 Pathway. Front. Oncol. 2019, 9, 754. [CrossRef] [PubMed]

144. Xu, L.; Che, X.; Wu, Y.; Song, N.; Shi, S.; Wang, S.; Li, C.; Zhang, L.; Zhang, X.; Qu, X.; et al. SIRT5 as a biomarker for response to anthracycline-taxane-based neoadjuvant chemotherapy in triple-negative breast cancer. Oncol. Rep. 2018, 39, $2315-2323$. [CrossRef] [PubMed]

145. Cea, M.; Cagnetta, A.; Adamia, S.; Acharya, C.; Tai, Y.T.; Fulciniti, M.; Ohguchi, H.; Munshi, A.; Acharya, P.; Bhasin, M.K.; et al. Evidence for a role of the histone deacetylase SIRT6 in DNA damage response of multiple myeloma cells. Blood 2016, 127, 1138-1150. [CrossRef] [PubMed]

146. Cagnetta, A.; Soncini, D.; Orecchioni, S.; Talarico, G.; Minetto, P.; Guolo, F.; Retali, V.; Colombo, N.; Carminati, E.; Clavio, M.; et al. Depletion of SIRT6 enzymatic activity increases acute myeloid leukemia cells vulnerability to DNA-damaging agents. Haematologica 2018, 103, 80-90. [CrossRef]

147. Lefort, K.; Brooks, Y.; Ostano, P.; Cario-André, M.; Calpini, V.; Guinea-Viniegra, J.; Albinger-Hegyi, A.; Hoetzenecker, W.; Kolfschoten, I.; Wagner, E.F.; et al. A miR-34a-SIRT6 axis in the squamous cell differentiation network. EMBO J. 2013, 32, 2248-2263. [CrossRef]

148. Elhanati, S.; Ben-Hamo, R.; Kanfi, Y.; Varvak, A.; Glazz, R.; Lerrer, B.; Efroni, S.; Cohen, H.Y. Reciprocal regulation between SIRT6 and miR-122 controls liver metabolism and predicts hepatocarcinoma prognosis. Cell Rep. 2016, 14, 234-242. [CrossRef]

149. Feng, X.X.; Luo, J.; Liu, M.; Yan, W.; Zhou, Z.Z.; Xia, Y.J.; Tu, W.; Li, P.Y.; Feng, Z.H.; Tian, D.A. Sirtuin 6 promotes transforming growth factor $-\beta 1 / \mathrm{H} 2 \mathrm{O} 2 / \mathrm{HOCl}$-mediated enhancement of hepatocellular carcinoma cell tumorigenicity by suppressing cellular senescence. Cancer Sci. 2015, 106, 559-566. [CrossRef]

150. Liu, Y.; Xie, Q.R.; Wang, B.; Shao, J.; Zhang, T.; Liu, T.; Huang, G.; Xia, W. Inhibition of SIRT6 in prostate cancer reduces cell viability and increases sensitivity to chemotherapeutics. Protein Cell. 2013, 4, 702-710. [CrossRef]

151. Wu, M.; Seto, E.; Zhang, J. E2F1 enhances glycolysis through suppressing Sirt6 transcription in cancer cells. Oncotarget 2015, 6, 11252-11263. [CrossRef]

152. Sebastian, C.; Zwaans, B.M.M.; Silberman, D.M.; Gymrek, M.; Goren, A.; Zhong, L.; Ram, O.; Truelove, J.; Guimaraes, A.R.; Toiber, D.; et al. The histone deacetylase SIRT6 is a tumor suppressor that controls cancer metabolism. Cell 2012, 151, 1185-1199. [CrossRef] 
153. Tian, J.; Yuan, L. Sirtuin 6 inhibits colon cancer progression by modulating PTEN/AKT signaling. Biomed. Pharm. 2018, 106, 109-116. [CrossRef] [PubMed]

154. Zhang, Y.; Nie, L.; Xu, K.; Fu, Y.; Zhong, J.; Gu, K.; Zhang, L. SIRT6, a novel direct transcriptional target of FoxO3a, mediates colon cancer therapy. Theranostics 2019, 9, 2380-2394. [CrossRef] [PubMed]

155. Choe, M.; Brusgard, J.L.; Chumsri, S.; Bhandary, L.; Zhao, X.F.; Lu, S.; Goloubeva, O.G.; Polster, B.M.; Fiskum, G.M.; Girnun, G.D.; et al. The RUNX2 Transcription Factor Negatively Regulates SIRT6 Expression to Alter Glucose Metabolism in Breast Cancer Cells. J. Cell. Biochem. 2015, 116, 2210-2226. [CrossRef] [PubMed]

156. Khongkow, M.; Olmos, Y.; Gong, C.; Gomes, A.R.; Monteiro, L.J.; Yagüe, E.; Cavaco, T.B.; Khongkow, P.; Man, E.P.; Laohasinnarong, S.; et al. SIRT6 modulates paclitaxel and epirubicin resistance and survival in breast cancer. Carcinogenesis 2013, 34, 1476-1486. [CrossRef]

157. Zhang, J.; Yin, X.J.; Xu, C.J.; Ning, Y.X.; Chen, M.; Zhang, H.; Chen, S.F.; Yao, L.Q. The histone deacetylase SIRT6 inhibits ovarian cancer cell proliferation via down-regulation of Notch 3 expression. Eur. Rev. Med. Pharm. Sci. 2015, 19, 818-824.

158. Kugel, S.; Sebastián, C.; Fitamant, J.; Ross, K.N.; Saha, S.K.; Jain, E.; Gladden, A.; Arora, K.S.; Kato, Y.; Rivera, M.N.; et al. SIRT6 suppresses pancreatic cancer through control of Lin28b. Cell 2016, 165, 1401-1415. [CrossRef]

159. Sundaresan, N.R.; Vasudevan, P.; Zhong, L.; Kim, G.; Samant, S.; Parekh, V.; Pillai, V.B.; Ravindra, P.V.; Gupta, M.; Jeevanandam, V.; et al. The sirtuin SIRT6 blocks IGF-Akt signaling and development of cardiac hypertrophy by targeting c-Jun. Nat. Med. 2012, 18, 1643-1650. [CrossRef]

160. D'Onofrio, N.; Servillo, L.; Balestrieri, M.L. SIRT1 and SIRT6 Signaling Pathways in Cardiovascular Disease Protection. Antioxid. Redox Signal. 2018, 28, 711-732. [CrossRef]

161. Yuan, H.; Su, L.; Chen, W.Y. The emerging and diverse roles of sirtuins in cancer: A clinical perspective. Onco Targets 2013, 6, 1399-1416.

162. Li, H.; Tian, Z.; Qu, Y.; Yang, Q.; Guan, H.; Shi, B.; Ji, M.; Hou, P. SIRT7 promotes thyroid tumorigenesis through phosphorylation and activation of Akt and p70S6K1 via DBC1/SIRT1 axis. Oncogene 2019, 38, 345-359. [CrossRef]

163. Malik, S.; Villanova, L.; Tanaka, S.; Aonuma, M.; Roy, N.; Berber, E.; Pollack, J.R.; Michishita-Kioi, E.; Chua, K.F. SIRT7 inactivation reverses metastatic phenotypes in epithelial and mesenchymal tumors. Sci. Rep. 2015, 5, 9841. [CrossRef] [PubMed]

164. Zhao, J.; Wozniak, A.; Adams, A.; Cox, J.; Vittal, A.; Voss, J.; Bridges, B.; Weinman, S.A.; Li, Z. SIRT7 regulates hepatocellular carcinoma response to therapy by altering the p53-dependent cell death pathway. J. Exp. Clin. Cancer Res. 2019, 38, 252. [CrossRef] [PubMed]

165. Wu, D.; Li, Y.; Zhu, K.S.; Wang, H.; Zhu, W.G. Advances in Cellular Characterization of the Sirtuin Isoform, SIRT7. Front. Endocrinol. 2018, 9, 652. [CrossRef] [PubMed]

166. Jing, H.; Lin, H. Sirtuins in epigenetic regulation. Chem. Rev. 2015, 115, 2350-2375. [CrossRef] [PubMed]

167. Meijer, A.J.; Lamers, W.H.; Chamuleau, R.A. Nitrogen metabolism and ornithine cycle function. Physiol. Rev. 1990, 70, 701-748. [CrossRef] [PubMed]

168. Rodgers, J.T.; Puigserver, P. Fasting-dependent glucose and lipid metabolic response through hepatic sirtuin 1. Proc. Natl. Acad. Sci. USA 2007, 04, 12861-12866. [CrossRef] [PubMed]

169. Zhao, E.; Hou, J.; Ke, X.; Abbas, M.N.; Kausar, S.; Zhang, L.; Cui, H. The Roles of Sirtuin Family Proteins in Cancer Progression. Cancers 2019, 11, 1949. [CrossRef]

170. Carafa, V.; Rotili, D.; Forgione, M.; Cuomo, F.; Serretiello, E.; Hailu, G.S.; Jarho, E.; Lahtela-Kakkonen, M.; Mai, A.; Altucci, L. Sirtuin functions and modulation: From chemistry to the clinic. Clin. Epigenetics 2016, 8, 61. [CrossRef]

171. Wiercińska, M.; Rosołowska-Huszcz, D. Natural and sythetic modulators of sirtuin activity. Kosm. Probl. Nauk Biol. 2017, 66, 365-377.

172. Davis, J.M.; Murphy, E.A.; Carmichael, M.D.; Davis, B. Quercetin increases brain and muscle mitochondrial biogenesis and exercise tolerance. Am. J. Physiol. Regul. Integr. Comp. Physiol. 2009, 296, 1071-1077. [CrossRef]

173. Kim, A.; Lee, W.; Yun, J.M. Luteolin and fisetin suppress oxidative stress by modulating sirtuins and forkhead box O3a expression under in vitro diabetic conditions. Nutr. Res. Pr. 2017, 11, 430-434. [CrossRef] [PubMed]

174. Gertz, M.; Nguyen, G.T.T.; Fischer, F.; Suenkel, B.; Schlicker, C.; Fränzel, B.; Tomaschewski, J.; Aladini, F.; Becker, C.; Wolters, D.; et al. A molecular mechanism for direct sirtuin activation by resveratrol. PLoS ONE 2012, 7, e49761. [CrossRef] [PubMed]

175. Dai, H.; Kustigian, L.; Carney, D.; Case, A.; Considine, T.; Hubbard, B.P.; Perni, R.B.; Riera, T.V.; Szczepankiewicz, B.; Vlasuk, G.P.; et al. SIRT1 activation by small molecules: Kinetic and biophysical evidence for direct interaction of enzyme and activator. J. Biol. Chem. 2010, 285, 32695-32703. [CrossRef] [PubMed]

176. Bitterman, K.J.; Anderson, R.M.; Cohen, H.Y.; Latorre-Esteves, M.; Sinclair, D.A. Inhibition of silencing and accelerated aging by nicotinamide, a putative negative regulator of yeast Sir2 and human SIRT1. J. Biol. Chem. 2002, 277, 45099-45107. [CrossRef]

177. Peck, B.; Chen, C.Y.; Ho, K.K.; Di Fruscia, P.; Myatt, S.S.; Coombes, R.C.; Fuchter, M.J.; Hsiao, C.D.; Lam, E.W. SIRT inhibitors induce cell death and p53 acetylation through targeting both SIRT1 and SIRT2. Mol. Cancer 2010, 9, 844-855. [CrossRef]

178. Lain, S.; Hollick, J.J.; Campbell, J.; Staples, O.D.; Higgins, M.; Aoubala, M.; McCarthy, A.; Appleyard, V.; Murray, K.E.; Baker, L.; et al. Discovery, in vivo activity, and mechanism of action of a small-molecule p53 activator. Cancer Cell. 2008, 13, 454-463. [CrossRef]

179. Pan, Y.; Zhang, H.; Zheng, Y.; Zhou, J.; Yuan, J.; Yu, Y.; Wang, J. Resveratrol Exerts Antioxidant Effects by Activating SIRT2 To Deacetylate Prx1. Biochemistry 2017, 56, 6325-6328. [CrossRef] 
180. Grozinger, C.M.; Chao, E.D.; Blackwell, H.E.; Moazed, D.; Schreiber, S.L. Identification of a class of small molecule inhibitors of the sirtuin family of NAD-dependent deacetylases by phenotypic screening. J. Biol. Chem. 2001, 276, 38837-38843. [CrossRef]

181. Rumpf, T.; Schiedel, M.; Karaman, B.; Roessler, C.; North, B.J.; Lehotzky, A.; Oláh, J.; Ladwein, K.I.; Schmidtkunz, K.; Gajer, M.; et al. Selective Sirt2 inhibition by ligand-induced rearrangement of the active site. Nat. Commun. 2015, 6, 6263. [CrossRef]

182. Heger, V.; Tyni, J.; Hunyadi, A.; Horáková, L.; Lahtela-Kakkonen, M.; Rahnasto-Rilla, M. Quercetin based derivatives as sirtuin inhibitors. Biomed. Pharmacother. 2019, 111, 1326-1333. [CrossRef]

183. Polletta, L.; Vernucci, E.; Carnevale, I.; Arcangeli, T.; Rotili, D.; Palmerio, S.; Steegborn, C.; Nowak, T.; Schutkowski, M.; Pellegrini, L.; et al. SIRT5 regulation of ammonia-induced autophagy and mitophagy. Autophagy 2015, 11, 253-270. [CrossRef] [PubMed]

184. Rahnasto-Rilla, M.; Tyni, J.; Huovinen, M.; Jarho, E.; Kulikowicz, T.; Ravichandran, S.; Bohr, V.A.; Ferrucci, L.; Lahtela-Kakkonen, M.; Moaddel, R. Natural polyphenols as sirtuin 6 modulators. Sci. Rep. 2018, 8, 4163. [CrossRef] [PubMed]

185. Lee, H.S.; Ka, S.O.; Lee, S.M.; Lee, S.I.; Park, J.W.; Park, B.H. Overexpression of sirtuin 6 suppresses inflammatory responses and bone destruction in mice with collagen-induced arthritis. Arthritis Rheum. 2013, 65, 1776-1785. [CrossRef] [PubMed]

186. Lappas, M. Anti-inflammatory properties of sirtuin 6 in human umbilical vein endothelial cells. Mediat. Inflamm. 2012, 2012, 597514. [CrossRef] [PubMed]

187. Cho, E.; Chung, E.Y.; Jang, H.Y.; Hong, O.Y.; Chae, H.S.; Jeong, Y.J.; Kim, S.Y.; Kim, B.S.; Yoo, D.J.; Kim, J.S.; et al. Anti-cancer Effect of Cyanidin-3-glucoside from Mulberry via Caspase-3 Cleavage and DNA Fragmentation in vitro and in vivo. Anticancer Agents Med. Chem. 2017, 17, 1519-1525. [CrossRef] [PubMed]

188. Liang, L.; Liu, X.; He, J.; Shao, Y.; Liu, J.; Wang, Z.; Xia, L.; Han, T.; Wu, P. Cyanidin-3-glucoside induces mesenchymal to epithelial transition via activating Sirt1 expression in triple negative breast cancer cells. Biochimie 2019, 162, 107-115. [CrossRef]

189. Przybylska, S. Curcumin—health-promoting pigment of turmeric. Probl. Hig. Epidemiol. 2015, 96, 414-420.

190. Hu, S.; Liu, H.; Ha, Y.; Luo, X.; Motamedi, M.; Gupta, M.P.; Ma, J.X.; Tilton, R.G.; Zhang, W. Posttranslational modification of Sirt6 activity by peroxynitrite. Free Rad. Biol. Med. 2015, 79, 176-185. [CrossRef]

191. Sahin, K.; Pala, R.; Tuzcu, M.; Ozdemir, O.; Orhan, C.; Sahin, N.; Juturu, V. Curcumin prevents muscle damage by regulating NF- $\mathrm{KB}$ and Nrf2 pathways and improves performance: An in vivo model. J. Inflamm. Res. 2016, 9, 147-154.

192. Xiao, J.; Sheng, X.; Zhang, X.; Guo, M.; Ji, X. Curcumin protects against myocardial infarction-induced cardiac fibrosis via SIRT1 activation in vivo and in vitro. Drug. Des. Devel. 2016, 10, 1267-1277.

193. Lin, X.L.; Liu, M.H.; Hu, H.J.; Feng, H.R.; Fan, X.J.; Zou, W.W.; Pan, Y.Q.; Hu, X.M.; Wang, Z. Curcumin enhanced cholesterol efflux by upregulating ABCA1 expression through AMPK-SIRT1-LXR $\alpha$ signaling in THP-1 macrophage-derived foam cells. Dna Cell. Biol. 2015, 34, 561-572. [CrossRef] [PubMed]

194. Avtanski, D.B.; Nagalingam, A.; Bonner, M.Y.; Arbiser, J.L.; Saxena, N.K.; Sharma, D. Honokiol activates LKB1-miR-34a axis and antagonizes the oncogenic actions of leptin in breast cancer. Oncotarget 2015, 6, 29947-29962. [CrossRef] [PubMed]

195. Averett, C.; Bhardwaj, A.; Arora, S.; Srivastava, S.K.; Khan, M.A.; Ahmad, A.; Singh, S.; Carter, J.E.; Khushman, M.; Singh, A.P. Honokiol Suppresses Pancreatic Tumor Growth, Metastasis and Desmoplasia by Interfering with Tumor-Stromal Cross-Talk. Carcinogenesis 2016, 37, 1052-1061. [CrossRef] [PubMed]

196. Fried, L.E.; Arbiser, J.L. Honokiol, a Multifunctional Antiangiogenic and Antitumor Agent. Antioxid. Redox Signal. 2009, 11, 1139-1148. [CrossRef] [PubMed]

197. Pillai, V.B.; Samant, S.; Sundaresan, N.R.; Raghuraman, H.; Kim, G.; Bonner, M.Y.; Arbiser, J.L.; Walker, D.I.; Jones, D.P.; Gius, D.; et al. Honokiol blocks and reverses cardiac hypertrophy in mice by activating mitochondrial Sirt3. Nat. Commun. 2015, 6, 6656. [CrossRef] [PubMed]

198. Xia, F.; Wang, C.; Jin, Y.; Liu, Q.; Meng, Q.; Liu, K.; Sun, H. Luteolin protects HUVECs from TNF- $\alpha$-induced oxidative stress and inflammation via its effects on the Nox4/ROS-NF-кB and MAPK pathways. J. Atheroscler. Thromb. 2014, 21, 768-783. [CrossRef]

199. Zang, Y.; Igarashi, K.; Li, Y. Anti-diabetic effects of luteolinand luteolin-7-O-glucoside on KK-Ay mice. Biosci. Biotechnol. Biochem. 2016, 80, 1580-1586. [CrossRef]

200. Mikula-Pietrasik, J.; Kuczmarska, A.; Książek, K. Biological multifunctionality of resveratrol and its derivatives. [Polish text]. Postepy Biochem. 2015, 61, 336-343.

201. Pelkonen, O.; Turpeinen, M.; Hakkola, J.; Honkakoski, P.; Hukkanen, J.; Raunio, H. Inhibition and induction of human cytochrome P450 enzymes: Current status. Arch. Toxicol. 2008, 82, 667-715. [CrossRef]

202. Borra, M.T.; Smith, B.C.; Denu, J.M. Mechanism of human SIRT1 activation by resveratrol. J. Biol. Chem. 2005, 280, 17187-17195. [CrossRef]

203. Cao, D.; Wang, M.; Qiu, X.; Liu, D.; Jiang, H.; Yang, N.; Xu, R.M. Structural basis for allosteric, substrate-dependent stimulation of SIRT1 activity by resveratrol. Genes Dev. 2015, 29, 1316-1325. [CrossRef] [PubMed]

204. Hou, X.; Rooklin, D.; Fang, H.; Zhang, Y. Resveratrol serves as a protein-substrate interaction stabilizer in human SIRT1 activation. Sci. Rep. 2016, 6, 38186. [CrossRef] [PubMed]

205. Mancuso, R.; Del Valle, J.; Modol, L.; Martinez, A.; Granado-Serrano, A.B.; Ramirez-Nunez, O.; Pallás, M.; Portero-Otin, M.; Osta, R.; Navarro, X. Resveratrol improves motoneuron function and extends survival in SOD1(G93A) ALS mice. Neurotherapeutics 2014, 11, 419-432. [PubMed]

206. Aykin-Burns, N.; Ahmad, I.M.; Zhu, Y.; Oberley, L.W.; Spitz, D.R. Increased levels of superoxide and H2O2 mediate the differential susceptibility of cancer cells versus normal cells to glucose deprivatio. Biochem. J. 2009, 418, 29-37. [CrossRef] [PubMed] 
207. Eren, M.K.; Kilincli, A.; Eren, Ö. Resveratrol Induced Premature Senescence Is Associated with DNA Damage Mediated SIRT1 and SIRT2 Down-Regulation. PLoS ONE 2015, 10, e0124837. [CrossRef]

208. Yan, W.J.; Liu, R.B.; Wang, L.K.; Ma, Y.B.; Ding, S.L.; Hu, Z.Y.; Wang, D.B. Sirt3-Mediated Autophagy Contributes to ResveratrolInduced Protection against ER Stress in HT22 Cells. Front. Neurosci. 2018, 12, 116. [CrossRef]

209. Dai, H.; David, A.; Sinclair, D.A.; James, L.; Ellis, J.L.; Steegborn, C. Sirtuin activators and inhibitors: Promises, achievements, and challenges. Pharmacol. Ther. 2018, 188, 140-154. [CrossRef]

210. Milne, J.C.; Lambert, P.D.; Schenk, S.; Carney, D.P.; Smith, J.J.; Gagne, D.J.; Jin, L.; Boss, O.; Perni, R.B.; Vu, C.B.; et al. Small molecule activators of SIRT1 as therapeutics for the treatment of type 2 diabetes. Nature 2007, 450, 712-716. [CrossRef]

211. Chauhan, D.; Bandi, M.; Singh, A.V.; Ray, A.; Raje, N.; Richardson, P.; Anderson, K.C. Preclinical evaluation of a novel SIRT1 modulator SRT1720 in multiple myeloma cells. Br. J. Haematol. 2011, 155, 588-598. [CrossRef]

212. Yamazaki, Y.; Usui, I.; Kanatani, Y.; Matsuya, Y.; Tsuneyama, K.; Fujisaka, S.; Bukhari, A.; Suzuki, H.; Senda, S.; Imanishi, S.; et al. Treatment with SRT1720, a SIRT1 activator, ameliorates fatty liver with reduced expression of lipogenic enzymes in MSG mice. Am. J. Physiol. Endocrinol. Metab. 2009, 297, 1179-1186. [CrossRef]

213. Kobylińska, A.; Janas, K.M. Health—Promoting effect of quercetin in human diet. Adv. Hyg. Exp. Med. 2015, 69, 51-62. [CrossRef] [PubMed]

214. Mieszkowski, J.; Pałys, A.; Budzisz, E. Quercetin—structure, function and clinical usage. Farm. Pol. 2011, 67, 18-24.

215. Dong, J.; Zhang, X.; Zhang, L.; Bian, H.X.; Xu, N.; Bao, B.; Liu, J. Quercetin reduces obesity-associated ATM infiltration and inflammation in mice: A mechanism including AMPK $\alpha 1 /$ SIRT1. J. Lipid Res. 2014, 55, 363-374. [CrossRef] [PubMed]

216. Peng, J.; Li, Q.; Li, K.; Zhu, L.; Lin, X.; Lin, X.; Shen, Q.; Li, G.; Xie, X. Quercetin Improves Glucose and Lipid Metabolism of Diabetic Rats: Involvement of Akt Signaling and SIRT1. J. Diabetes Res. 2017, 2017, 3417306. [CrossRef] [PubMed]

217. Kamelo, M.K.; Horinek, A.; Canova, N.K.; Farghali, H. Comparative effects of Quercetin and SRT1720 against Dgalactosamine/lipopolysaccharide-induced hepatotoxicity in rats: Biochemical and molecular biological investigations. Eur. Rev. Med. Pharm. Sci. 2016, 20,363-371.

218. Hu, J.; Jing, H.; Lin, H. Sirtuin inhibitors as anticancer agents. Future Med. Chem. 2014, 6, 945-966. [CrossRef]

219. Holloway, K.R.; Barbieri, A.; Malyarchuk, S.; Saxena, M.; Nedeljkovic-Kurepa, A.; Cameron Mehl, M.; Wang, A.; Gu, X.; Pruitt, K. SIRT1 positively regulates breast cancer associated human aromatase (CYP19A1) expression. Mol. Endocrinol. 2013, 27, 480-490. [CrossRef]

220. Shukla, A.S.; Jha, K.A.; Kumari, R.; Rawat, K.; Syeda, S.; Shrivastava, A. Role of Catechins in Chemosensitization. In Role of Nutraceuticals in Cancer Chemosensitization; Bharti, A.C., Aggarwal, B.B., Eds.; Elsevier: Amsterdam, The Netherlands, 2018; Volume 2, pp. 169-198.

221. Pietrzak, L.; Mogielnicki, A.; Buczko, W. Nicotinamide and its metabolite N-methylnicotinamide increase skin vascular permeability in rats. Clin. Exp. Derm. 2009, 34, 380-384. [CrossRef]

222. Jung-Hynes, B.; Nihal, M.; Zhong, W.; Ahmad, N. Role of sirtuin histone deacetylase SIRT1 in prostate cancer. A target for prostate cancer management via its inhibition? J. Biol. Chem. 2009, 284, 3823-3832. [CrossRef]

223. Audrito, V.; Vaisitti, T.; Rossi, D.; Gottardi, D.; D’Arena, G.; Laurenti, L.; Gaidano, G.; Malavasi, F.; Deaglio, S. Nicotinamide blocks proliferation and induces apoptosis of chronic lymphocytic leukemia cells through activation of the p53/miR-34a/SIRT1 tumor suppressor network. Cancer Res. 2011, 71, 4473-4483. [CrossRef]

224. Lara, E.; Mai, A.; Calvanese, V.; Altucci, L.; Lopez-Nieva, P.; Martinez-Chantar, M.L.; Varela-Rey, M.; Rotili, D.; Nebbioso, A.; Ropero, S.; et al. Salermide, a Sirtuin inhibitor with a strong cancer-specific proapoptotic effect. Oncogene 2009, 28, 781-791. [CrossRef] [PubMed]

225. Süssmuth, S.D.; Haider, S.; Landwehrmeyer, G.B.; Farmer, R.; Frost, C.; Tripepi, G.; Andersen, C.A.; Di Bacco, M.; Lamanna, C.; Diodato, E.; et al. An exploratory double-blind, randomized clinical trial with selisistat, a SirT1 inhibitor, in patients with Huntington's disease. Br. J. Clin. Pharm. 2015, 79, 465-476. [CrossRef] [PubMed]

226. Tsay, S.C.; Hwu, J.R. Pharmaceutical and Biological Effects of Suramin and Potential of Its Derivatives and Analogues. Org. Med. Chem. Int. J. 2017, 2, 555593. [CrossRef]

227. Schuetz, A.; Min, J.; Antoshenko, T.; Wang, C.L.; Allali-Hassani, A.; Dong, A.; Loppnau, P.; Vedadi, M.; Bochkarev, A.; Sternglanz, R.; et al. Structural basis of inhibition of the human NAD+-dependent deacetylase SIRT5 by suramin. Structure 2007, 15, 377-389. [CrossRef]

228. Sunami, Y.; Araki, M.; Hironaka, Y.; Morishita, S.; Kobayashi, M.; Liew, E.L.; Edahiro, Y.; Tsutsui, M.; Ohsaka, A.; Komatsu, N. Inhibition of the NAD-Dependent Protein Deacetylase SIRT2 Induces Granulocytic Differentiation in Human Leukemia Cells. PLoS ONE 2013, 8, e57633. [CrossRef]

229. Nihal, M.; Ahmad, N.; Wood, G.S. SIRT1 is upregulated in cutaneous T-cell lymphoma, and its inhibition induces growth arrest and apoptosis. Cell Cycle 2014, 3, 632-640. [CrossRef] 